\title{
Interventions for improving employment outcomes for workers with HIV (Review)
}

\author{
Robinson R, Okpo E, Mngoma N
}

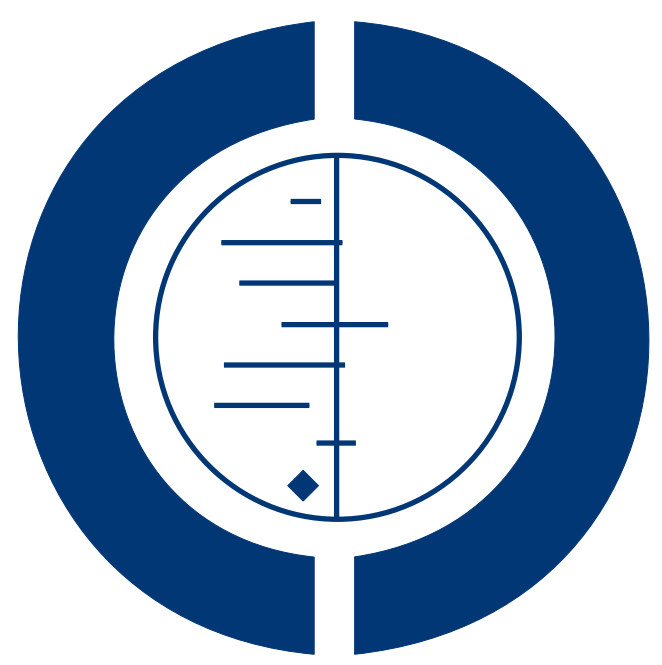

\section{THE COCHRANE COLLABORATION $^{\circledR}$}

This is a reprint of a Cochrane review, prepared and maintained by The Cochrane Collaboration and published in The Cochrane Library 2015, Issue 5

http://www.thecochranelibrary.com

\section{WILEY}


TABLE OF CONTENTS

HEADER . . . . . . . . . . . . . . . . . . . . . . . . . . . . . . . . . . . . . . 1

ABSTRACT . . . . . . . . . . . . . . . . . . . . . . . . . . . . . . . . . . . . . . . . . . . . . . . . . . 1

PLAIN LANGUAGE SUMMARY . . . . . . . . . . . . . . . . . . . . . . . . . . . . . . . . . . . .

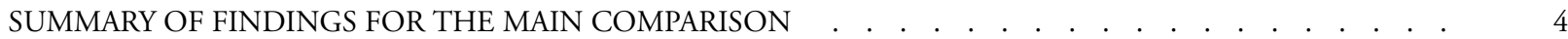

BACKGROUND . . . . . . . . . . . . . . . . . . . . . . . . . . . . . . . . . . . . 5

OBJECTIVES . . . . . . . . . . . . . . . . . . . . . . . . . . . . . . . . . . . . . . . . . . . .

METHODS . . . . . . . . . . . . . . . . . . . . . . . . . . . . . . . . . . . . . . . . .

Figure 1. . . . . . . . . . . . . . . . . . . . . . . . . . . . . . . . . . . . . . 8

RESULTS . . . . . . . . . . . . . . . . . . . . . . . . . . . . . . . . . . . . . . . 11

Figure 2. . . . . . . . . . . . . . . . . . . . . . . . . . . . . . . . . . . . . . .

DISCUSSION . . . . . . . . . . . . . . . . . . . . . . . . . . . . . . . . . . . . . . .

AUTHORS' CONCLUSIONS . . . . . . . . . . . . . . . . . . . . . . . . . . . . . . . . . . . . .

ACKNOWLEDGEMENTS . . . . . . . . . . . . . . . . . . . . . . . . . . . . . . . . . . . . . . .

REFERENCES . . . . . . . . . . . . . . . . . . . . . . . . . . . . . . . . . . . . . . . 23

CHARACTERISTICS OF STUDIES . . . . . . . . . . . . . . . . . . . . . . . . . . . . . . 26

DATA AND ANALYSES . . . . . . . . . . . . . . . . . . . . . . . . . . . . . . . . . . . . 41

Analysis 1.1. Comparison $1 \mathrm{HIV}+$ utilizing ART versus healthy (non-HIV+), Outcome 1 Regaining Employment. .42

Analysis 1.2. Comparison $1 \mathrm{HIV}+$ utilizing ART versus healthy (non-HIV+), Outcome 2 Days working per month. 43

Analysis 1.3. Comparison $1 \mathrm{HIV}+$ utilizing ART versus healthy (non-HIV+), Outcome 3 Resides in Surveillance Area. 44

Analysis 1.4. Comparison $1 \mathrm{HIV}+$ utilizing ART versus healthy (non-HIV+), Outcome 4 Job-loss Spells. $\quad$. . . $\quad$. 45

Analysis 2.1. Comparison $2 \mathrm{HIV}+$ utilizing ART versus HIV+ pre-ART, Outcome 1 Employment at 12 months followup. . . . . . . . . . . . . . . . . . . . . . . . . . . . . . . . . . . . . . 45

Analysis 2.2. Comparison $2 \mathrm{HIV}+$ utilizing ART versus HIV+ pre-ART, Outcome 2 Hours worked in past week. . . 46

ADDITIONAL TABLES . . . . . . . . . . . . . . . . . . . . . . . . . . . . . . . . . . . . . . . . . . . 46

APPENDICES . . . . . . . . . . . . . . . . . . . . . . . . . . . . . . . . . . . . . . . . . . . . . . .

CONTRIBUTIONS OF AUTHORS . . . . . . . . . . . . . . . . . . . . . . . . . . . . . . . . . . . . . . . . . . .

DECLARATIONS OF INTEREST . . . . . . . . . . . . . . . . . . . . . . . . . . . . . . . . . . . . . . . . . . .

DIFFERENCES BETWEEN PROTOCOL AND REVIEW . . . . . . . . . . . . . . . . . . . . . . . . . . . 55

Interventions for improving employment outcomes for workers with HIV (Review)

Copyright @ 2015 The Cochrane Collaboration. Published by John Wiley \& Sons, Ltd. 


\title{
[Intervention Review]
}

\section{Interventions for improving employment outcomes for workers with HIV}

\author{
Rachel Robinson ${ }^{1}$, Emmanuel Okpo $^{2}$, Nomusa Mngoma ${ }^{3}$ \\ ${ }^{1}$ Finnish Institute of Occupational Health, Kuopio, Finland. ${ }^{2}$ Public Health Directorate, NHS Grampian, Aberdeen, UK. ${ }^{3}$ School of \\ Kinesiology and Health Studies, Queen's University, Kingston, Canada \\ Contact address: Rachel Robinson, Finnish Institute of Occupational Health, Neulaniementie 4, Kuopio, 70101, Finland. \\ racher@student.uef.fi. rachelkristin@gmail.com.
}

Editorial group: Cochrane Occupational Safety and Health Group.

Publication status and date: New, published in Issue 5, 2015.

Review content assessed as up-to-date: 9 December 2014.

Citation: Robinson R, Okpo E, Mngoma N. Interventions for improving employment outcomes for workers with HIV. Cochrane Database of Systematic Reviews 2015, Issue 5. Art. No.: CD010090. DOI: 10.1002/14651858.CD010090.pub2.

Copyright (C) 2015 The Cochrane Collaboration. Published by John Wiley \& Sons, Ltd.

\begin{abstract}
A B S T R A C T
Background

The vast majority of people infected with human immunodeficiency virus (HIV) are adults of working age. Therefore unemployment and job loss resulting from HIV infection are major public health and economic concerns. Return to work (RTW) after diagnosis of $\mathrm{HIV}$ is a long and complex process, particularly if the individual has been absent from work for long periods. There have been various efforts to improve the RTW of persons living with HIV (HIV+), and many of these have been assessed formally in intervention studies.
\end{abstract}

\section{Objectives}

To evaluate the effect of interventions aimed at sustaining and improving employment in HIV+ persons.

\section{Search methods}

We conducted a comprehensive search from 1981 until December 2014 in the following databases: Cochrane Central Register of Controlled Trials (CENTRAL), MEDLINE, EMBASE, CINAHL, OSH UPDATE databases (CISDOC, HSELINE, NIOSHTIC, NIOSHTIC-2, RILOSH), and PsycINFO.

\section{Selection criteria}

We considered for inclusion all randomized controlled trials (RCTs) or controlled before-after (CBA) studies assessing the effectiveness of pharmacological, vocational and psychological interventions with HIV+ working-aged (16 years or older) participants that had used RTW or other indices of employment as outcomes.

\section{Data collection and analysis}

Two review authors independently screened all potential references for inclusion. We determined final selection of studies by consensus. We performed data extraction and management, as well as Risk of bias assessment, in duplicate. We measured the treatment effect using odds ratio (OR) for binary outcomes and mean difference (MD) for continuous outcomes. We applied the GRADE approach to appraise the quality of the evidence.

Interventions for improving employment outcomes for workers with HIV (Review)

Copyright @ 2015 The Cochrane Collaboration. Published by John Wiley \& Sons, Ltd. 


\section{Main results}

We found one RCT with 174 participants and five CBAs with 48,058 participants assessing the effectiveness of vocational training (n $=1)$ and antiretroviral therapy (ART) $(n=5)$. We found no studies assessing psychological interventions. The one RCT was conducted in the United States; the five CBA studies were conducted in South Africa, India, Kenya, and Uganda. We graded all six studies as having a high risk of bias.

The effectiveness of vocational intervention was assessed in only one study but we could not infer the intervention effect due to a lack of data.

For pharmacological interventions, we found very low-quality evidence for a beneficial effect of ART on employment outcomes in five studies. Due to differences in outcome measurement we could only combine the results of two studies in a meta-analysis.

Two studies compared employment outcomes of HIV+ persons on ART therapy to healthy controls. One study found a MD of 1.22 days worked per month ( $95 \%$ confidence interval (CI) -1.74 to -1.07$)$ at 24 -months follow-up. The other study found that the likelihood of being employed steadily increased for HIV+ persons compared to healthy individuals from ART initiation (OR 0.35, 95\% CI 0.26 to 0.47 ) to three- to five-years follow-up (OR $0.73,95 \%$ CI 0.42 to 1.28 ).

Three other studies compared HIV+ persons on ART to HIV+ persons not yet on ART. Two studies indicated an increase in the likelihood of employment over time due to the impact of ART for HIV+ persons compared to HIV+ persons pre-ART (OR 1.75, 95\% CI 1.44 to 2.12). One study found that the group on ART worked 12.1 hours more (95\% CI 6.99 to 17.21) per week at 24-months follow-up than the average of the cohort of ART and pre-ART HIV+ persons which was 20.1 hours.

We rated the evidence as very low quality for all comparisons due to a high risk of bias.

\section{Authors' conclusions}

We found very low-quality evidence showing that ART interventions may improve employment outcomes for HIV+ persons. For vocational interventions, the one included study produced no evidence of an intervention effect. We found no studies that assessed psychological interventions. We need more high-quality, preferably randomized studies to assess the effectiveness of RTW interventions for HIV+ persons.

\section{PLAIN LANGUAGE SUMMARY}

Interventions for improving employment outcomes for workers with HIV

\section{Background}

For people living with HIV(HIV+), losing their job can make it even harder to cope with the illness. This review aimed to assess how we can prevent HIV+ people from losing their jobs or help them return to work. There are three approaches to achieve these aims. The first one is to use drugs, meaning antiretroviral therapy, to keep the disease and its symptoms from getting worse. The second is to make changes to work tasks or the work environment. The third is to offer psychological support to help the HIV+ person cope better with their condition, especially at work. We included studies that assessed the effects of one or more of these approaches. The effect of interventions can be measured as whether HIV+ persons are employed or not, and as the number of days or hours HIV+ persons were able to work following an intervention.

\section{Studies we found}

We found five controlled before-after (CBA) studies from South Africa, India, Uganda, and Kenya and one randomized controlled trial from the USA. The studies included over 48,000 participants. Five studies examined antiretroviral therapy and one study examined vocational interventions as a way of improving return to work in $\mathrm{HIV}+$ people.

\section{Key findings}

The five CBA studies found that antiretroviral therapy interventions may increase employment outcomes in HIV+ people. One study assessed the effect of making changes to work tasks or the work environment but did not report enough data to say if it helped or not. We found no studies on psychological support to help HIV+ people cope better.

\section{Quality of the evidence}

Interventions for improving employment outcomes for workers with HIV (Review)

Copyright ( 2015 The Cochrane Collaboration. Published by John Wiley \& Sons, Ltd. 
Overall, we found very low-quality evidence because the included studies all had a high risk of bias.

\section{Conclusion}

We found very low-quality evidence that antiretroviral therapy interventions could improve employment outcomes for HIV+ people. We need high-quality, randomized trials to find out if pharmacological, vocational, and psychological interventions can improve employment outcomes for HIV+ people. 
SUMMARY OF FINDINGS FOR THE MAIN COMPARISON [Explanation]

\section{Anti-retroviral therapy compared with no ART for HIV}

Patient or population: Working age adults with HIV

Settings: Uganda

Intervention: ART

Comparison: Not on ART

\begin{tabular}{|c|c|c|c|c|c|c|c|}
\hline \multirow[t]{3}{*}{ Outcomes } & \multicolumn{3}{|c|}{ Illustrative comparative risks* $(95 \% \mathrm{Cl})$} & \multirow{3}{*}{$\begin{array}{l}\text { Relative effect } \\
(95 \% \text { Cl) }\end{array}$} & \multirow{3}{*}{$\begin{array}{l}\text { No of Participants } \\
\text { (studies) }\end{array}$} & \multirow{3}{*}{$\begin{array}{l}\text { Quality of the evidence } \\
\text { (GRADE) }\end{array}$} & \multirow[t]{3}{*}{ Comments } \\
\hline & Assumed Likelihood & $\begin{array}{l}\text { Corresponding } \\
\text { hood }\end{array}$ & Likeli- & & & & \\
\hline & Not on ART & $\begin{array}{l}\text { Anti-retroviral } \\
\text { (ART) }\end{array}$ & therapy & & & & \\
\hline $\begin{array}{l}\text { Employed at } 12 \text { months } \\
\text { follow-up }\end{array}$ & 710 per 1000 & $\begin{array}{l}811 \text { per } 1000 \\
\text { (779 to } 838)\end{array}$ & & OR 1.75 (1.44 to 2.12) & $\begin{array}{l}1084 \\
\text { (2 studies) }\end{array}$ & $\begin{array}{l}\oplus \bigcirc \bigcirc \bigcirc \\
\text { very low } 1\end{array}$ & \\
\hline
\end{tabular}

*The basis for the assumed likelihood (e.g. the median control group risk across studies) is provided in footnotes. The corresponding likelihood (and its $95 \%$ confidence interval) is based on the assumed risk in the comparison group and the relative effect of the intervention (and its $95 \% \mathrm{Cl}$ ).

Cl: Confidence interval; RR: Risk Ratio; ART: Anti-retroviral therapy

GRADE Working Group grades of evidence

High quality: Further research is very unlikely to change our confidence in the estimate of effect.

Moderate quality: Further research is likely to have an important impact on our confidence in the estimate of effect and may change the estimate.

Low quality: Further research is very likely to have an important impact on our confidence in the estimate of effect and is likely to change the estimate.

Very low quality: We are very uncertain about the estimate.

${ }^{1}$ Downgraded the quality of evidence because of limitations in study design as a non-randomized studies, as well as a high risk of bias

for baseline comparability, unclear risk for incomplete outcome data due to a lack of reporting of attrition for controls, and high risk

for adjustment for confounding . 


\section{B A C K G R O U N D}

As the vast majority of those infected with human immunodeficiency virus (HIV) are adults of working age, unemployment and job loss resulting from HIV infection are major public health and economic concerns (Braveman 2006; Kaiser Family Foundation 2007; Yelin 1991).

The HIV literature suggests that HIV infection in individuals of working age is associated with loss of employment, particularly in women (Dray-Spira 2006). As with other serious illnesses, HIV also leads to increased absenteeism from work, reduced productivity, increased financial burden on employers, increased job loss, and loss of earnings (Feeley 2004; Fox 2004; Kaiser Family Foundation 2007; Sendi 2004). However, recent advances in the treatment and management of the disease in the last decade have made it possible for infected people to live longer and have healthier lives. As a result, HIV infection can now be considered a longterm illness rather than a terminal one.

The benefits of employment on the health and social well-being of adults of working age has been documented by, among others, Rueda 2012 and Waddell 2006. Generally, frequent or long-term absence from work leads to job loss and may result in depression, financial insecurity, and social isolation (Henderson 2005; Linn 1985). Unemployment has been linked to suicidal tendencies and poor memory performance, especially in men with HIV (Kelly 1998; Rabkin 2004). A study carried out by Blalock 2002 showed that employment in people living with HIV was associated with improvement in quality of life, positive effect on self esteem, and increased confidence and dignity.

\section{Barriers to return to work}

Return to work (RTW) after diagnosis of HIV is a long and complex process, particularly if the individual has been absent from work for long periods (Gorman 2009). Several factors have been identified in the current literature as barriers to RTW in HIVinfected individuals. These include health concerns, such as unpredictability of the disease, which is often associated with repeated episodes of illness leading to physical and cognitive impairment; side effects of medication; and the fear of losing disability allowance following RTW (Braveman 2006; Gorman 2009). Other factors include the fear of discrimination and stigmatization at the workplace by one's employer and colleagues following disclosure of HIV/AIDS status (Rabkin 2004; Rao 2008; Rodger 2010).

In the last decade, international organizations have made great headway in addressing the barriers associated with RTW for those living with HIV, particularly barriers related to the workplace. The International Labour Organization's 'Recommendation Concerning HIV and AIDS and the World of Work', in ILO 2010, and 'Code of Practice on HIV/AIDS and the World of Work', in ILO 2001 , set out recommendations and good practice. These include such principles as non-discrimination in employment, promotion of retention in work of people living with HIV, respect for the human right and dignity of people living with HIV, and universal access to prevention, treatment, care, and support. These recommendations are meant to be used as the basis for policy development in addressing the epidemic at the workplace (ILO 2001; ILO 2010).

\section{Description of the intervention}

Generally speaking, interventions that promote return to work for any sick person include all activities undertaken to improve the work ability of that individual. These activities often include interventions targeted at the employee, employer, and the workplace. A number of arrangements and interventions have been investigated in relation to sustaining employment in people living with HIV. Kielhofner 2004 conducted a three-year RTW program for people living with HIV using a combination of psycho-educational and occupational therapy. The authors concluded that this approach addressed a wide range of physical, psychosocial, and environmental issues.

Different types of vocational and psychosocial rehabilitation have been investigated in relation to return to work for people living with HIV. Although most of these studies have been qualitative in nature, the results have been positive. In one study that investigated the impact of vocational services on employment in people living with HIV/AIDS, the authors reported that vocational services had a positive impact on employment (Conyers 2004). The Matrix Research Institute (MRI) conducted the Kirk Employment Empowerment Project (KEEP), a vocational rehabilitation practices demonstration project for HIV+ persons and employment. KEEP's multidimensional intervention service approach included job search assistance, benefits and legal counselling, disability management education, on-site job support, job-related problem solving, skills training, referrals to auxiliary services, and coordination of other service providers. The MRI results demonstrated improvement in employment outcomes due to vocational rehabilitation services (Escovitz 2005). Group counselling as an intervention aimed at enhancing RTW has also been found to impact positively on RTW in HIV+ persons. Kohlenberg 2003 investigated group counselling as an intervention to support RTW in people living with HIV with physical and cognitive symptoms. A significant aspect of this intervention involved the development of personalized occupational training and employment plans.

Additionally, researchers have examined the use of antiretroviral therapy (ART) in employment retention and re-entry. Pharmacological interventions such as ART exhibit compelling results in improving the likelihood of employment-related economic productivity for HIV+ persons (Bernell 2005; Van der Borght 2006).

\section{Why it is important to do this review}


Successful RTW or sustainability of employment in HIV+ depends not only on co-operation between the employer and the employee, but also the availability of evidence-based interventions that encourage and promote return to work. Although there are several reviews on interventions that promote RTW following diagnosis of long-term conditions such as cancer and musculoskeletal problems (De Boer 2011; Schaafsma 2010), no systematic review has been published that looks specifically at interventions aimed at promoting RTW or sustaining employment for HIV+ persons.

\section{O B J E C T I VES}

To evaluate the effect of interventions aimed at sustaining and improving employment in HIV+ persons.

\section{METHODS}

\section{Criteria for considering studies for this review}

\section{Types of studies}

We assessed all eligible randomized controlled trials (RCTs) for inclusion in this review. However, due to the complexity of conducting RCTs in work organizations, we also accepted cluster RCTs and controlled before-after (CBA) studies.

\section{Types of participants}

We included studies conducted with HIV+ persons aged 16 years and over who were employed or unemployed at the time of diagnosis, irrespective of the stage of disease at the time of diagnosis.

\section{Types of interventions}

We included studies that evaluated any intervention or arrangement aimed at sustaining work or employment in people living with HIV. We considered interventions that were targeted at the workplace or at the individual or groups of individuals within the workplace or community, including policies aimed at preserving employment in specific categories of workers. We categorized interventions as follows:

1. Medical or pharmacological interventions such as provision of free ART or antidepressants.

2. Vocational interventions such as vocational or occupational rehabilitation, workplace adjustments such as protected time for medication, change in work schedule or duties, modified work hours, or improved communication with or between managers, colleagues, and health professionals.
3. Psychological interventions such as education, counselling, cognitive-behavioral interventions, training in coping skills, or group psychotherapy.

4. A combination of any of the above.

\section{Types of outcome measures}

\section{Primary outcomes}

1. RTW, measured either as the number of days to partial or full work resumption or as the number of days absent during follow-up.

2. Job loss, measured as the number of people who lost their job during the time of follow-up. As the complement of job loss is being employed, we also included studies that had measured being employed or the amount of time spent at work.

\section{Secondary outcomes}

1. Overall quality of life (physical and emotional).

2. Cost of intervention programs and cost effectiveness of RTW or employment.

\section{Search methods for identification of studies}

\section{Electronic searches}

We searched for relevant studies in the following databases:

- Cochrane Central Register of Controlled Trials

(CENTRAL; 2014, Issue 12)

- MEDLINE (1980 to December 2014)

- EMBASE (1980 to December 2014)

- CINAHL (1983 to December 2014)

- OSH UPDATE databases (CISDOC, HSELINE, NIOSHTIC, NIOSHTIC-2, RILOSH; 1980 to present)

- PsycINFO (1980 December 2014)

We have presented the search strategies for MEDLINE, CENTRAL, EMBASE, and OSH UPDATE as Appendix 1, Appendix 2, Appendix 3, and Appendix 4. We designed the strategies to include appropriate $\mathrm{MeSH}$ subject headings and text word terms, interventions under consideration, and included study designs. We restricted the searches to years from 1981 onwards, reflecting the year when the first acquired immunodeficiency syndrome (AIDS) cases were reported in the United States. We imposed no language restrictions. 


\section{Searching other resources}

We screened the reference lists of selected articles and reviews to locate additional potentially eligible studies.

We considered articles and studies published in any language. We intended for relevant articles published in languages other than English to be translated, but we found no such articles. When we required further information to determine inclusion, we wrote to the corresponding authors.

\section{Data collection and analysis}

\section{Selection of studies}

We carried out the selection of eligible studies in two stages.

Stage 1: Three review authors (Rachel Robinson (RR), Emmanuel Okpo (EO), and Nomusa Mngoma (NM)) independently screened the titles and abstracts of studies the search strategy identified for relevance, that is whether the study assessed the effectiveness of an intervention aimed at sustaining employment in HIVinfected individuals and measured RTW. If the title and abstract provided sufficient information to determine that the study did not satisfy the criteria for inclusion, we excluded the study. Review authors resolved differences in opinion through discussion.

Stage 2: We retrieved full texts of all the studies selected in stage 1. Each review author then independently examined whether the selected studies met the inclusion criteria. At this stage, we documented the reasons for study exclusion. We resolved differences in opinion by discussion and consensus.

We have presented a PRISMA study flow diagram to describe the sequence of steps in the screening process and reasons for the exclusion of studies in Figure 1. 
Figure I. PRISMA study flow diagram

Search of Databases: Cochrane Central Register of Controlled Trials (CENTRAL), MEDLINE, EMBASE, CINAHL, OSH UPDATE databases, PSycINFO

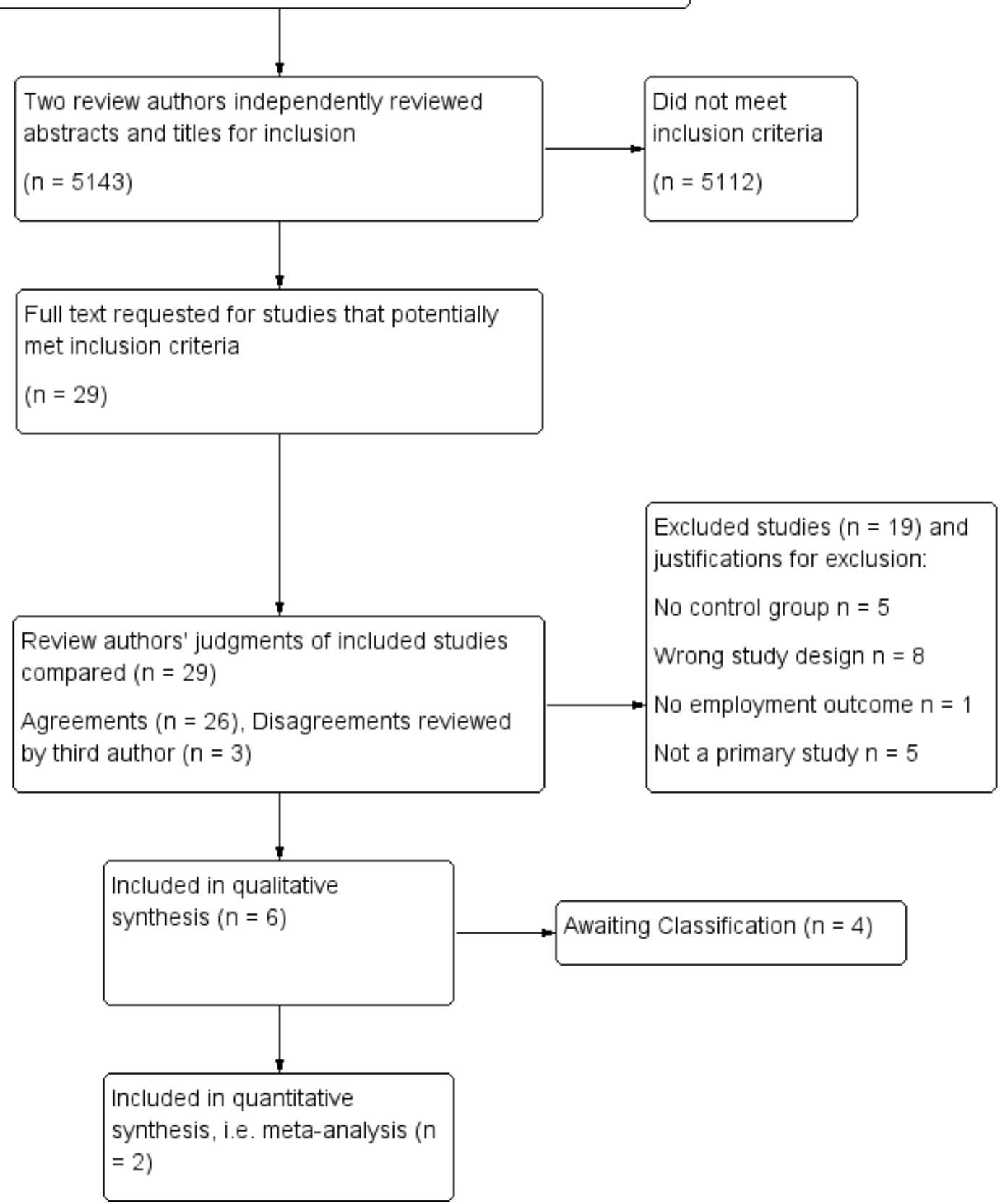




\section{Data extraction and management}

We designed a data extraction form specifically for this review that captured key elements such as study design, country, setting, sociodemographic characteristics of participants including ethnicity, interventions (content, duration, provider, context), followup, and all outcomes of interest, particularly RTW measures. Review authors (RR, EO, and NM) independently extracted data from the eligible studies.

\section{Assessment of risk of bias in included studies}

All three review authors (RR, EO, and NM) independently assessed the risk of bias of all the included studies by following the procedures described in the Cochrane Handbook for Systematic Reviews of Interventions (Higgins 2011). We assessed RCTs and cluster RCTs against the six domains listed below. We rated studies as having 'low risk of bias' (plausible bias unlikely to seriously alter the results); 'high risk of bias' (plausible bias that seriously weakens confidence in the results); or 'unclear risk of bias' (plausible bias that raises some doubt about results).

- Sequence generation: Was the allocation sequence adequately described?

- Allocation concealment: Was allocation adequately concealed?

- Blinding of participants, personnel, and outcome assessors: Was knowledge of the allocation intervention adequately prevented during the study?

- Incomplete outcome data: Was incomplete outcome data adequately addressed?

- Selective outcome reporting: Are reports of the study free of suggestion of selective outcome reporting?

- Other sources of bias: Did the study appear to be free of other problems that could put it at high risk of bias?

For non-randomized studies, we utilized the checklist developed by Downs 1998 to measure the quality of the studies. The criteria consist of several scales, but our review team used only the following two:

- Internal validity in terms of bias (seven items)

- Internal validity in terms of confounding and selection bias (six items)

We added an additional item on baseline comparability of intervention and control group, but we did not use the item on power of the study. We combined all items with the Cochrane 'Risk of bias' tool in the Characteristics of included studies section. For confounding and baseline comparability, we used the following factors that according to our judgment could increase or decrease employment: gender, age, socioeconomic status, migration status, disease severity.
Instead of the original score as 'yes', 'no', or 'unable to determine', we used 'low', 'high', and 'unclear' risk of bias to make the checklist compatible with the Cochrane 'Risk of bias' tool as implemented in RevMan 2014.

We determined blinding of participants to be 'low risk' for retrospective studies because participants were unaware of the intervention at the time. Conversely, we considered blinding of participants to be 'high risk' if study authors did not report having used blinding or if it was clear from the report that the study was unblinded. See point 14 in our 'Risk of bias' assessments in the Characteristics of included studies section.

\section{Measures of treatment effect}

We plotted the results of each study as point estimates. For binary outcomes, that is where the probability of an event occurring or not occurring is considered, we used risk ratios (RRs) as the measure of effect; if this was not reported, we used odds ratios (ORs). For continuous outcomes, we plotted the results of individual studies using mean differences (MDs). The reporting of effect sizes did not require the use of standardized mean difference as we found no studies using similar continuous outcome measures. When we could not plot the results, we described them in the text.

\section{Unit of analysis issues}

As we found no cluster RCTs to include in the review, we did not have to contend with unit of analysis problems.

If in future updates we encounter studies that employ a clusterrandomized design and that report sufficient data for us to include in the meta-analysis but do not make an allowance for the design effect, we will calculate the design effect based on a fairly large assumed intracluster correlation of 0.10 . We based this assumption of 0.10 being a realistic estimate by analogy on studies about implementation research (Campbell 2001). We will follow the methods stated in the Cochrane Handbook for Systematic Reviews of Interventions for the calculations (Higgins 2011).

If in future updates we find studies with repeat observations on participants, we will compute an effect measure for each participant factoring in all the time points and will present this as trends over time or overall means, depending on the data.

\section{Dealing with missing data}

When the issue of missing data arose, we discussed the reasons why the data could be missing and determined a way of dealing with it accordingly. Where we suspected missing data due to a lack of publication, publication in obscure places, or data presented inappropriately, we did whatever was possible to contact the original authors of the studies.

Interventions for improving employment outcomes for workers with HIV (Review) 
If in future updates of this review we discover that participants are missing from the reported results, such as when analyses of randomized trials do not include all randomized participants (no intention-to-treat analyses), we will consider performing intentionto-treat analysis on the presented data. We will also consider:

- analyzing only the available data (i.e. ignoring the missing data);

- imputing the missing data with replacement values and treating these as if they were observed;

- imputing the missing data and accounting for the fact that these were imputed with uncertainty;

- using statistical models to allow for missing data while making assumptions about their relationships with the available data.

We will explicitly state the assumptions of any methods used to cope with missing data and perform sensitivity analyses to assess how sensitive results are to changes in the assumptions.

\section{Assessment of heterogeneity}

We assessed clinical homogeneity based on similarity the of population, intervention, outcome, and follow-up. We considered populations as similar when they were people living with HIV aged 16 years and over irrespective of the stage of the disease at the time of diagnosis. We considered the various intervention categories (as outlined in Types of interventions) as different. We deemed the various outcome categories as different. For the RTW outcome, both the number of days to partial or full work resumption and number of days absent during follow-up had to be sufficiently similar to combine them as similar outcomes. We regarded followup times as different if they were less than three months, three months to one year, and more than one year.

In conducting meta-analyses, we considered the extent to which the results of studies are consistent by comparing confidence intervals for the results of individual studies and observing overlap as indication of the presence of statistical heterogeneity. We performed a $\mathrm{Chi}^{2}$ test to further check for statistical heterogeneity. When the P value indicated that there was heterogeneity, we used the result of the $\mathrm{I}^{2}$ measure to quantify the degree of heterogeneity. A percentage of $0 \%$ to $40 \%$ indicated that heterogeneity might not be important; $30 \%$ to $60 \%$ signifed moderate heterogeneity; $50 \%$ to $90 \%$ substantial heterogeneity; and $75 \%$ to $100 \%$ considerable heterogeneity.

\section{Assessment of reporting biases}

We compared the outcomes listed in the methods section of an article with the reported results. We considered inadequately reported, non-significant results as a potential source of bias. We included published and unpublished data on the intervention under review to reduce publication bias. If sufficient data are available in future updates of this review, we will use funnel plots to detect reporting bias. We reduced the effect of reporting bias by including studies and not publications in order to avoid the introduction of duplicated data (that is two articles could represent duplicate publications of the same study). Following the Cho 2000 statement on redundant publications, we extracted data only once for duplicate studies or if multiple articles reported on the same study. We prevented location bias by searching across multiple databases. Additionally, we prevented language bias by not excluding any article based on language.

\section{Data synthesis}

As this review includes different types of studies (randomized and non-randomized studies), we analysed the data separately for the different study designs. We pooled suitably homogenuous data using Review Manager 5.3 software (RevMan 2014). We present the results of our only meta-analysis in the Summary of findings for the main comparison.

We had sufficient data to perform meta-analysis based on only two studies. As the two studies included in the meta-analysis were statistically homogeneous, we used a fixed-effect model. We included the $95 \%$ confidence interval $(\mathrm{CI})$ around the effect estimate. In future updates of the review, if studies are heterogenous, we will use a random-effects model. When using the random-effects model, we will conduct a sensitivity check by using the fixed-effect model to reveal differences in results.

We assessed the quality of evidence using the GRADE approach as described in the Cochrane Handbook for Systematic Reviews of Interventions (Higgins 2011). See additional Table 1.

We downgraded the quality of evidence for the RTW outcome based on the following factors:

- Limitations of the study design and implementation:

allocation concealment, blinding, loss to follow-up, and selective reporting

- Indirectness of evidence: indirect population, intervention, control, and outcomes

- Inconsistency of results: subgroup analysis, heterogeneity, and inconsistent results

- Imprecision of results: wide confidence intervals

- Publication bias

We considered upgrading the quality of evidence for CBA studies based on the following factors:

- Magnitude of the effect

- Dose-effect relation

- All confounding excluded

The GRADE approach specifies four levels of quality (high, moderate, low, and very low).

Subgroup analysis and investigation of heterogeneity 
Although we had planned to carry out a series of subgroup analyses, the included studies did not provide sufficient data to do so. In future updates, wherever possible, we will carry out subgroup analysis to account for differences in the primary outcome of RTW and disability rates between:

- gender, i.e. men versus women;

- different stages of the disease, e.g. clinically asymptomatic (WHO stages 1 and 2) versus symptomatic including AIDS (WHO stages 3 and 4);

- type of employment before diagnosis was made, e.g. healthrelated versus non-health-related employment;

- economic setting, e.g. low income, lower middle income, and upper middle income versus high income.

If we can conduct subgroup meta-analyses in future updates, we will quantify the degree of heterogeneity using the $\mathrm{I}^{2}$ statistic, where an $\mathrm{I}^{2}$ value of $30 \%$ to $60 \%$ indicates moderate heterogeneity, $50 \%$ to $90 \%$ substantial heterogeneity, and greater than $75 \%$ considerable heterogeneity (Higgins 2011. We will investigate substantial heterogeneity further using meta-regression assuming that we have included an adequate number of studies.

\section{Sensitivity analysis}

In our protocol we planned to conduct a sensitivity analysis to monitor the robustness of the results. However, our meta-analysis only includes two studies. Therefore, we did not conduct a sensitivity analysis.

\section{RES U L T S}

\section{Description of studies}

\section{Results of the search}

We searched six key databases up to December 2014: the Cochrane Central Register of Controlled Trials (CENTRAL), MEDLINE, EMBASE, CINAHL, PsycINFO, and OSH Update (CISDOC, HSELINE, NIOSHTIC, NIOSHTIC 2, RILOSH). The intial search in 2012 yielded a total of 5799 studies. After removal of duplicate references, 4787 studies remained. In June 2013 and December 2014 we conducted update searches of all the aforementioned databases, resulting in an additional 460 and 331 references, respectively. We obtained a combined total of 5578 references for title and abstract inspection.

Evaluation of the reference titles and abstracts identified 29 studies for full-text examination. Nine studies did not meet the study design criteria of RCT or CBA studies. We disqualified two studies due to topic irrelevance. We excluded an additional five studies due to lack of a control group. We eliminated one final study that focused on chronic diseases and RTW because HIV-specific outcome data was unavailable (we requested raw data from the authors but they could not provide HIV-specific data). Ten studies remained for further consideration (Bor 2012; Baran 2012; Borwein 2010; Larson 2013; Linnemayr 2013; Martin 2012; Nannungi 2013; Paul-Ward 2005; Popiel 2010; Thirumurthy 2011). We categorized four of these as 'Studies awaiting classification' (see Characteristics of studies awaiting classification); three due to a lack of full-text article and one because it was in progress in 2005, but we could not locate a final publication of outcome data. We requested full-text articles from the authors of these studies as well as unpublished raw outcome data, but we received none. The remaining six studies (one RCT and five CBA studies) formed the list of the final six included studies on which we performed data extraction and 'Risk of bias' assessment (Bor 2012; Larson 2013; Linnemayr 2013; Martin 2012; Nannungi 2013; Thirumurthy 2011). See Figure 1 for the PRISMA study flow diagram.

\section{Included studies}

See Characteristics of included studies.

\section{Study designs}

We found one RCT (Martin 2012) and five CBA studies (Bor 2012; Larson 2013; Linnemayr 2013; Nannungi 2013; Thirumurthy 2011). The RCT utilized a stratified randomization procedure; the researchers stratified participants in both control and index groups on education, CD4 count, and ethnic minority status to account for potential influence of these covariates. All five CBA studies were ART studies (Bor 2012; Larson 2013; Linnemayr 2013; Nannungi 2013; Thirumurthy 2011). Both Larson 2013 and Bor 2012 were retrospective analyses of cohorts. Whereas Linnemayr 2013, Nannungi 2013, and Thirumurthy 2011 were prospective cohort studies.

\section{Number of participants}

Martin 2012 studied $174 \mathrm{HIV}+$ persons comprising of 83 index participants and 91 references. Bor 2012, Larson 2013, Linnemayr 2013, Nannungi 2013, and Thirumurthy 2011 studied a total of 3336 index participants and 44,722 references.

\section{Types of participants}

The vocational therapy RCT conducted by Martin 2012 recruited participants through advertisements at AIDS service organizations, community and mental health centers, HIV medical providers, gay and lesbian centers, community forums for HIVpositive adults, and through advertisements in publications targeted at HIV+ persons in the United States.

Two studies analyzed HIV+ workers referenced against the nonHIV general work force (Bor 2012; Larson 2013). Larson 2013 
examined a cohort of tea pluckers in two major Kenyan tea plantations. Bor 2012 used data from all inhabitants of Hlabisa subdistrict in South Africa and combined employment data extracted from the Africa Centre for Health and Population Studies surveillance system with data on being HIV+ from the Hlabisa HIV Treatment and Care Program records.

Three studies compared HIV+ persons on ART to HIV+ persons not yet eligible for ART (Linnemayr 2013; Nannungi 2013; Thirumurthy 2011). Linnemayr 2013 and Nannungi 2013 examined participants from four Ugandan HIV treatment clinics, one rural (Kakira) and three urban (Kampala). Thirumurthy 2011 compared HIV+ persons who had initiated ART with HIV+ persons who were classified as pre-ART and were a part of the Tamil Nadu Family Care Continuum (TNFCC) Program in Tamil Nadu, India. In all five CBA studies, participants were of working age (16 years or older) and were HIV+. Additionally, Thirumurthy 2011 also included 67 children in their analysis as well as 54 caretakers.

\section{Interventions}

The included studies evaluated five pharmacological ART interventions and one mixed vocational and psychological intervention (Bor 2012; Larson 2013; Linnemayr 2013; Martin 2012; Nannungi 2013; Thirumurthy 2011). We found no psychological interventions. The vocational intervention consisted of 13 group sessions with at least 1 individual session, carried out over a 7 week period (Martin 2012). The group sessions included presentations, brainstorming, discussions, role playing, and homework assignments regarding motivation and barriers to RTW, concerns of a HIV+ persons in the work force, skills for retaining a job, and "thinking like an employer" training.

The pharmacological intervention CBAs consisted of measuring employment outcomes prior to ART initiation, at the time of ART initiation, and at several follow-up intervals (Bor 2012; Larson 2013; Linnemayr 2013; Nannungi 2013; Thirumurthy 2011). HIV+ persons in the Larson 2013 study received free ART through their workplace hospitals and clinics. Participants in the Bor 2012 study received free ART from the Hlabisa HIV Treatment and Care Program. In the Linnemayr 2013 study, participants received basic HIV primary medical care and ART from two Joint Clinical Research Centre HIV clinics in Uganda, one rural (Kakira) and one urban (Kampala). The participants in Nannungi 2013 acquired HIV primary medical care and ART from two HIV clinics in urban Kampala, Uganda. Thirumurthy 2011 participants received free ART from the TNFCC Program. Additionally, all of the Thirumurthy 2011 participants received other clinical care services, nutritional supplements, and home-based care, which for the indexed participants involved ART adherence support.

\section{Time period and location}

All six included studies were conducted between 2000 and 2013. The studies were conducted in South Africa, the United States, India, Kenya, and Uganda.

\section{Outcomes reported}

\section{RCT}

The Martin 2012 study measured employment as any type of employment in the past 6 months, job training class attendance, and active job searching in the past 30 days.

Although Martin 2012 reported having measured employment outcomes at $6,12,18$, and 24 months post-ART initiation, but the authors published only baseline data. We requested the 6-, $12-$ , 18-, and 24-month follow-up outcome data from the authors, but we did not receive a response.

\section{CBA}

Bor 2012 measured employment solely as employed versus unemployed. Employment was measured 24, 18, 12, and 6 months before beginning ART and $0,6,18,24$, and 30 to 60 months following ART initiation. The authors reported the ORs from logistic regression with T-values. We calculated the standard error needed for input into the data tables by dividing the $\log \mathrm{OR}$ by the reported T-value.

Larson 2013 measured employment as days worked in the past month and stratified the results by gender. The researchers measured employment 24,18,12, and 6 months before beginning ART and $0,6,18,24$, and 30 to 60 months following ART initiation.

Linnemayr 2013 measured employment status based on whether or not the HIV+ persons had participated in employment activity in the week prior to the interview. The researchers measured employment for all participants at 0,6 , and 12 months and reported as changes in employment status. The authors reported the ORs from logistic regression with $\mathrm{T}$-values. We calculated the standard error needed for input into the data tables by dividing the $\log \mathrm{OR}$ by the reported T-value. The authors graphically reported 0,6 , and 12 months outcomes for currently working, pain interference with work, health interference with work, and work sel-efficacy. We contacted the authors for the raw data of these outcomes but we did not receive a response.

Nannungi 2013 measured employment status as a binary outcome based on whether or not the HIV+ persons had participated in employment activity in the week prior to the interview. The researchers measured employment for all participants at 0,6 , and 12 months.

Thirumurthy 2011 measured employment as hours worked in the last week and stratified the results by gender. The researchers measured employment at $6,12,18$, and 24 months following 
ART initiation. We contacted the authors for further explanation of their Table 3 but we did not receive a response.

None of the included studies, whether RCT or CBA, measured our secondary outcomes of quality of life or costs.

\section{Excluded studies}

We gave 19 studies particular consideration before exclusion as detailed in the Characteristics of excluded studies section. We excluded nine of these studies on the basis of irrelevant study design, that is they were not RCTs or CBA intervention studies (Bernell 2005; Martin 2003; Resch 2011; Rosen 2004; Rosolen 2002; Rueda 2012; Thirumurthy 2013; Van der Borght 2006;
Van der Borght 2010). Six studies did not have control groups (Ajithkumar 2007; Escovitz 2005; Goldman 2004; Hergenrather 2013; Rosen 2010; Rosen 2014). We excluded one purely qualitative study (Maticka-Tyndale 2002). We excluded Herdt 1999 due to lack of topic relevance. We excluded Lee 2005 due to a lack of specific HIV data. We also excluded a summary of an ongoing study (Martin 2005) that was later published as Martin 2012.

\section{Risk of bias in included studies}

See Figure 2 for an overall view of our assessment of the included studies' risk of bias.

Figure 2. 'Risk of bias' summary: review authors' judgments about each 'Risk of bias' item for each included study.

\begin{tabular}{|c|c|c|c|c|c|c|c|c|c|c|c|c|c|c|}
\hline & 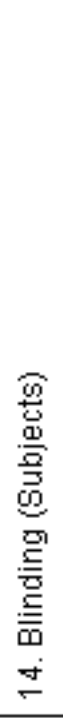 & 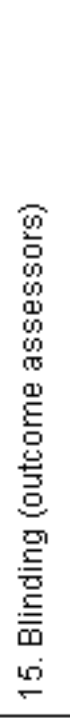 & 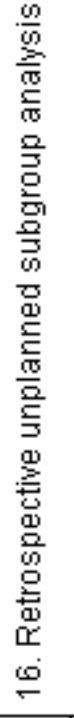 & 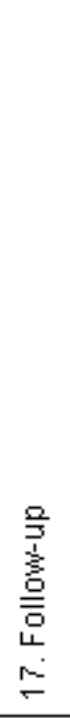 & 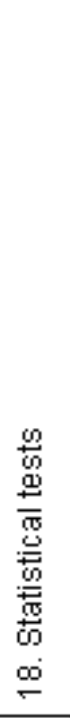 & 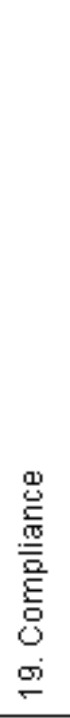 & 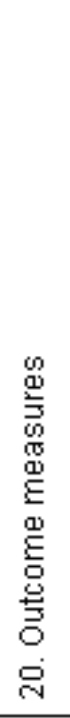 & 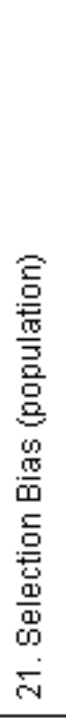 & 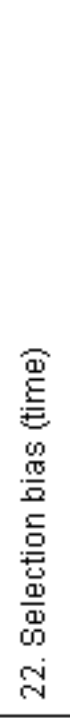 & 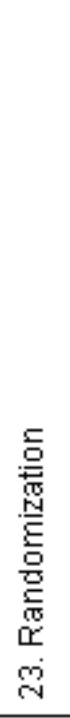 & 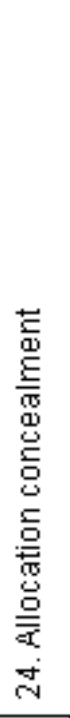 & 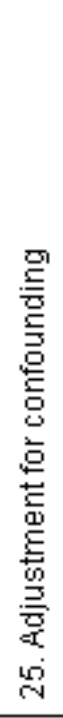 & 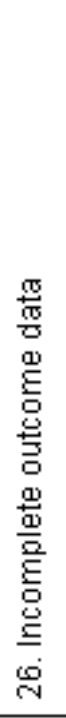 & 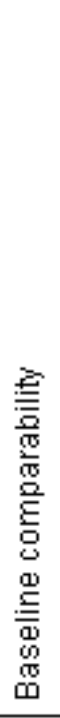 \\
\hline Bor 2012 & + & + & $?$ & + & + & $?$ & + & + & + & - & $?$ & - & & \\
\hline Larson 2013 & $\oplus$ & + & $?$ & + & + & $?$ & + & + & + & - & $?$ & - & - & \\
\hline Linnemayr 2013 & $?$ & $\oplus$ & 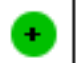 & + & + & $?$ & + & $?$ & $?$ & $?$ & $?$ & $?$ & $\oplus$ & $?$ \\
\hline Martin 2012 & & & $?$ & + & $?$ & - & + & $?$ & + & + & $?$ & & & \\
\hline Nannungi 2013 & $?$ & + & + & $?$ & + & $?$ & + & + & + & $\odot$ & - & $?$ & $?$ & \\
\hline Thirumurthy 2011 & $\oplus$ & $\oplus$ & + & + & $?$ & $?$ & + & + & $\odot$ & & $?$ & - & $?$ & $?$ \\
\hline
\end{tabular}

Interventions for improving employment outcomes for workers with HIV (Review)

Copyright $\odot 2015$ The Cochrane Collaboration. Published by John Wiley \& Sons, Ltd. 


\section{Allocation}

\section{RCT}

The researchers of the RCT reported adequate details on their randomization sequence generation (Martin 2012). However, we judged their allocation concealment to be unclear. As the study recruited participants from multiple AIDS service organizations, community mental health centers, HIV medical providers, and gay/lesbian centers, some participant features may be disproportionately represented in index and reference groups. However, reported baseline demographics were similar between groups. We therefore determined the risk of population selection bias as unclear. We found no evidence of time selection bias, as recruitment of all participants occurred during the same time frame.

\section{CBA}

Prior analysis predetermined allocation to reference and control groups in both retrospective cohort studies (Bor 2012; Larson 2013). The participants' CD4 counts and health status preordained allocation to index and reference groups in the prospective studies (Linnemayr 2013; Nannungi 2013; Thirumurthy 2011). All HIV+ persons utilizing ART (CD4 count less than 250 cells/ $\mathrm{mm}^{3}$ ) were assigned to the index group and all HIV+ persons preART (CD4 count less than 400 cells $/ \mathrm{mm}^{3}$ but greater than 250 cells $/ \mathrm{mm}^{3}$ ) were assigned to the control group. We considered the risk of selection bias for the population as low in all five observational studies. Three studies' use of HIV+ persons seeking care for both the index and reference groups reduces selection bias by eliminating the potential differences between people who choose to seek care and those who choose not to seek care (Linnemayr 2013; Nannungi 2013; Thirumurthy 2011). Bor 2012 gathered participants in both the index and reference groups from the Africa Center for Health and Population Studies' population surveillance system. Bor 2012 included all HIV+ people who were utilizing ART during the 10-year follow-up period of the Africa Centre for Health and Population Studies's population surveillance study and who sought care through the Hlabisa HIV Treatment and Care Programme as index participants. Larson 2013 collected all participants from the work forces of two Kenyan tea plantations. For index participants, Larson 2013 used all HIV+ workers who visited the tea plantation hospitals and healthcare clinics. Linnemayr 2013 used clinic staff to approach eligible clients for study participation at the appointment in which ART eligibility was assessed. Nannungi 2013 enrolled consecutive new clinic clients who had recently been evaluated for ART eligibility. Thirumurthy 2011 procured index and reference group participants from the Tamil Nadu Family Care Continuum Program.

There was no randomization in any of the five studies, as all HIV+ persons who were utilizing ART were assigned to the index group out of physical necessity. However, we judged the studies as at low risk of selection bias, as all HIV+ persons using ART were assigned to the index group. Recruitment of index and reference participants occurred at the same time in all five observational studies, showing no time-based selection bias.

\section{Blinding}

\section{RCT}

As Martin 2012 did not report blinding of participants or outcome assessors, we assessed the risk of bias due to blinding as high.

\section{CBA}

For two of the CBA studies, due to the retrospective comparisons of HIV+ persons on ART versus healthy people, we considered the participants to be blind to the idea of a special intervention, as they were not aware of the study at the time (Bor 2012; Larson 2013). For the prospective HIV+ persons on ART versus HIV+ persons pre-ART comparison, Linnemayr 2013, Nannungi 2013, and Thirumurthy 2011 did not blind participants, as health status required knowledge of treatment. Nevertheless, due to the objective employment/unemployment outcome in all five CBA studies, we believe the lack of blinding has not biased the results. Blinding of the outcome assessors was unclear in all five CBA studies, however we believe that this lack of assessor blinding did not bias results due to objective administrative outcomes.

\section{Incomplete outcome data}

\section{RCT}

Martin 2012 did not report employment rates past the baseline and did not address attrition and reasons for missing data. We therefore assessed the risk of bias due to incomplete outcome data as high.

\section{CBA}

All five of the non-randomized CBAs addressed attrition rates of the index groups (Bor 2012; Larson 2013; Linnemayr 2013; Nannungi 2013; Thirumurthy 2011). Larson 2013 missed data on $6 \%$ of index participants due to death, resignation, or retirement. Larson 2013 reported no attrition data on the control group. Bor 2012 excluded data on $20 \%$ of index participants due to attrition, mortality, late cohort entry, and lack of employment information, but did not report attrition data for the reference group. Linnemayr 2013 reported low attrition with approximately $95 \%$ retention of study participants and used an intention-to-treat analysis. However, Nannungi 2013 reported 30\% attrition at 6 months, which increased to $36 \%$ at 12 months. The high level of attrition in Nannungi 2013 was evenly distributed between 
the ART and non-ART groups, at 37\% and 35\%, respectively. Thirumurthy 2011 had an attrition of $34 \%$ and did not report any outcome data for controls.

Due to a lack of reporting of attrition for the controls in three studies (Bor 2012; Larson 2013; Thirumurthy 2011), we judged the risk of bias to be high for incomplete outcome data.

Two studies reported no data for compliance to ART intervention (Bor 2012; Larson 2013). Neither Linnemayr 2013 nor Nannungi 2013 measured compliance with ART. Thirumurthy 2011 provided ART adherence support but did not provide data for compliance. However, in all five ART intervention studies (Bor 2012; Larson 2013; Linnemayr 2013; Nannungi 2013; Thirumurthy 2011), we can reasonably assume that compliance to ART medications would be high, as the health of the participant is highly dependent upon adherence. Martin 2012 monitored compliance and conducted a dose-response analysis, but insufficiently reported the results and explanation.

We judged all five CBA studies to have an unclear risk of bias for compliance with the intervention, due to a lack of reporting of compliance measures combined wtih the necessity of ART for survival, which may encourage intervention compliance.

\section{Selective reporting}

We judged Martin 2012 to have a high risk of reporting bias due to complete lack of reporting of any follow-up outcome data.

All five CBA studies, Bor 2012, Larson 2013, Linnemayr 2013, Nannungi 2013, and Thirumurthy 2011, reported all of the original outcomes determined at the onset of the study for the index groups.

The two retrospective observational studies conducted retrospective unplanned subgroup analysis (Bor 2012; Larson 2013), whereas the single RCT is most likely guilty of data dredging due to complete lack of outcome reporting and presenting results based on complicated and unjustified statistical analysis (Martin 2012). We determined that the three prospective CBA studies did not indicate any unplanned retrospective subgroup analysis (Linnemayr 2013; Nannungi 2013; Thirumurthy 2011).

\section{Other potential sources of bias}

\section{RCT}

The single RCT did not report any co-occurring interventions (Martin 2012). Also, the authors did not account for ART utilization in the health status outcome, which could have influenced the results. Hence, we judged Martin 2012 to have a high risk of other bias.

\section{CBA}

Baseline comparability assessment of the index and reference groups shows a high risk of bias for all five CBA studies (Bor 2012; Larson 2013; Linnemayr 2013; Nannungi 2013; Thirumurthy 2011). As the studies inconsistently reported baseline characteristics, it is unclear if the baseline characteristics were appropriately comparable within comparisons. The baseline characteristics of intervention participants presented in the Linnemayr 2013 study showed significantly fewer are working, higher levels of pain interfering with work, higher levels of health interfering with work, lower levels of self efficacy, lower CD4 counts, lower levels of primary education, higher rates of depression, and lower overall physical function. The authors claim to have performed a sensitivity analysis restricting the control group to those with a similar health status as the intervention group, but for whom ART had been deferred. The authors of the Linnemayr 2013 study alleged that the results of the sensitivity analysis did not differ from the intention-to-treat analysis, meaning that the differences in health status at baseline did not affect the intervention effect. However, they did not publish this data. The Nannungi 2013 study baseline characteristics showed a higher percentage of controls working at baseline with better overall health. The beneficial outcome reported may be confounded by the difference in disease severity at baseline between the pre-ART participants and the participants initiating ART. The health of HIV+ persons on ART may improve over time, while pre-ART participants' health may decline, leading to an inflation of the intervention effect. The Linnemayr 2013 study avoided similar inflation of the intervention effect by performing intention-to-treat analysis, keeping all participants in their original groups regardless of ART status at end of followup. However, the use of intention-to-treat analysis may have undermined the overall effect of the intervention. Once again, the authors of the Linnemayr 2013 study claim to have performed a second sensitivity analysis that excluded all participants in the control group who initiated ART during the study period. The analysis supposedly resulted in similar findings to the intentionto-treat analysis and therefore the authors did not provide the data and the finding cannot be verified within the text.

We assigned a high risk of bias to three of the observational CBA studies due to a lack of adjustment for confounding. Bor 2012 adjusted for migration but did not adjust for age, sex, socioeconomic status, or disease severity. Larson 2013 adjusted for gender but did not adjust for age, socioeconomic status, migration, or disease severity. Thirumurthy 2011 adjusted for gender but did not adjust for age, socioeconomic status, migration, or disease severity. We deemed an unclear risk of bias for two of the prospective observational studies for adjustment for confounding, as they adjusted for some but not all potential confounders. Linnemayr 2013 stratified data by gender and urban/rural and included physical and mental health confounders. Nannungi 2013 adjusted for changes in physical health status, age, gender, education, relationship status, and CD4 count.

None of the five CBA studies reported possible cointerventions 
that may have influenced the employment outcome.

Due to the file drawer phenomenon, bias often results in the publication of only positive-outcome studies. All studies included in this review provided positive intervention effects, leading to a possible artificially augmented effect. However, in regards to the ART intervention, the well-documented improvement in health status due to ART supports the positive findings.

\section{Overall risk of bias in included studies}

\section{RCT}

We determined the overall risk of bias in the single included RCT based on allocation concealment/randomization, blinding, loss to follow-up, and selective reporting. We had decided a priori to consider studies to have a low risk of bias if we graded all four items as low.

The above criteria resulted in a judgment of high overall risk of bias for Martin 2012. The study had an unclear risk of allocation concealment and a high risk of bias due to a lack of blinding and selective reporting.

\section{CBA}

We determined the overall risk of bias in the CBA studies based on selection bias (items 21 and 22), adjustment for confounding (25), and baseline comparability using the Downs 1998 checklist. We disregarded randomization and allocation concealment, as by definition the studies are non-randomized. We did not include blinding of outcome assessors, participants, and providers because the outcome is objectively obtained. We had decided a priori to consider a CBA study to have a low overall risk of bias if we graded all four items as low.

See Figure 2 for an overall view of our assessment of the included studies' risk of bias.

Bor 2012 had a high overall risk of bias. We judged the study to have a low risk of selection bias, a high risk of bias associated with adjustment for confounding, and a high risk of bias for baseline comparability.

Larson 2013 had a high overall risk of bias. We judged the study to have a low risk of selection bias, a high risk of bias due to a lack of adjustment for confounding, and a high risk of bias for baseline comparability.

Linnemayr 2013 had a high overall risk of bias. We judged the study to have a high risk of population selection bias, an unclear risk of time selection bias, an unclear risk of bias for adjustment for confounding, and an unclear risk for baseline comparability. Nannungi 2013 had a high overall risk of bias. We judged the study to have a high risk of population selection bias, a low risk of time selection bias, an unclear risk of bias due to adjustments for confounding, and a high risk of bias for baseline comparability. Thirumurthy 2011 also had a high overall risk of bias. We judged the study to have a low risk of selection bias, a high risk of bias due to adjustment for confounding, and an unclear risk of bias for baseline comparability.

\section{Effects of interventions}

See: Summary of findings for the main comparison

\section{Pharmacological interventions}

\section{A. HIV+ persons utilizing ART versus healthy (non-HIV+) individuals}

Two CBA studies compared the effect of ART interventions in HIV+ persons on employment status to a control group of healthy, untreated participants (Bor 2012; Larson 2013). Both studies used existing data on health and employment outcomes before and after ART initiation. Bor 2012 used retrospective data from a cohort from the Hlabisa Treatment and Care Program surveillance area in South Africa over 10 years. Larson 2013 drew data from hospitals and employer records of two major Kenyan tea plantations. The studies defined employment status as employed/unemployed and as the number of days worked per month. As an employment measure, the number of days worked highlights the ability of the participant to maintain work in comparison to the healthy controls.

We could not combine the results of these studies in meta-analysis due to the use of different outcome measures and statistical methods within the studies.

\section{Primary outcome: being employed}

\section{4 to 18 months before start of ART}

Neither Bor 2012 or Larson 2013 found a statistically significant difference between HIV + persons and healthy participants in employment status. Bor 2012 found no difference in being employed or not, OR 0.79 (95\% CI 0.61 to 1.02; Analysis 1.1), whereas Larson 2013 found no difference in number of days worked per month, MD - 0.05 days ( $95 \%$ CI -0.50 to 0.40 ; Analysis 1.2 ).

\section{6 to 0 months before start of ART}

Bor 2012 and Larson 2013 both found a significant decrease in employment 6 months prior to the start of ART for HIV+ persons in comparison to healthy participants in the work force. Bor 2012 reported the HIV+ person more likely to be unemployed, with an OR of 0.50 (95\% CI 0.26 to 0.47 ; Analysis 1.1). Similarly, Larson 2013 found HIV + persons to have worked significantly less, with a MD of -1.28 days ( $95 \%$ CI -1.65 to -0.91 ; Analysis 1.2 ).

\section{At ART initiation}


At the time of ART initiation, both studies observed a continual downward trend, with the lowest levels of employment for HIV+ participants. Bor 2012 found an OR 0.35 (95\% CI 0.26 to 0.47 ), meaning a three-fold lower rate of employment in the HIV+ participants when compared to the healthy persons. The findings of Larson 2013 were similar, with a MD of -8.49 (95\% CI -9.57 to -7.41 ), translating to an 8 to 9 days' difference in days worked per month between the index and reference groups.

\section{6 months after ART initiation}

Bor 2012 reported an OR of 0.38 (95\% CI 0.28 to 0.52; Analysis 1.1 ), indicating that HIV+ persons were still less likely to be employed after 6 months on ART than the reference group.

However, in Larson 2013, the difference in employment between healthy participants and HIV+ persons decreased immediately after the start of ART. Larson 2013 reported a MD of 0.08 days (95\% CI 0.05 to 0.11 ; Analysis 1.2), meaning that HIV+ persons on ART had worked only slightly less than participants of the healthy reference group.

\section{8 to 24 months after ART initiation}

Bor 2012 reported an OR of 0.44 (95\% CI 0.31 to 0.62; Analysis 1.1), representing a significantly lower likelihood of being employed for HIV+ participants on ART when compared to the healthy work force.

Larson 2013 reported a MD of -1.22 days (95\% CI -1.74 to 1.07; Analysis 1.2), meaning that the HIV+ persons had worked a little less per month than the healthy workers in the reference group.

\section{6 to 60 months after ART initiation}

Bor 2012 found similar employment rates in both groups, with an OR of 0.73 (95\% CI 0.42 to 1.28 ) at 36 to 60 months postART initiation (Analysis 1.1).

Additionally, Bor 2012 measured "unemployment due to illness", "job loss spells", and "resides in surveillance area"; we did not include these figures in our review due to their reciprocal nature to the employment outcomes measured above (Analysis 1.3; Analysis 1.4). We made this decision to prevent double counting of outcomes. The OR of 2.17 (95\% CI 1.31 to 3.58) for unemployment due to illness at ART initiation declines to 0.70 (95\% CI 0.32 to $1.55)$ by 18 to 24 months post-ART.

\section{B. HIV+ persons utilizing ART versus HIV+ persons pre-ART}

We found three CBA studies (2748 participants) comparing HIV+ persons on ART with HIV+ persons pre-ART.

Thirumurthy 2011 measured RTW by the number of hours worked in the past week. The study obtained follow-up data every 6 months, culminating at 24 months post-ART initiation. The authors used linear regression analysis and a dummy coding system that coded for either all workers at different follow-up or for those on ART only at follow-up. Thus the results are expressed as the number of hours that the group on ART worked more than the average cohort. Some of the participants got ART in between follow-up. The authors excluded these participants from the analysis.

Nannungi 2013 and Linnemayr 2013 measured RTW as a binary 'yes' or 'no' outcome, by whether or not the participant engaged in work activities in the last seven days prior to the interview. Nannungi 2013 reported percentages of participants who had RTW who were not employed at baseline as a change in work status at 6 and 12 months. Linnemayr 2013 reported the data graphically; we could not obtain raw data for this review. In future updates of this review, we will present the outcomes for participants currently working at baseline ( 0 months), 6 months, and 12 months, if we are able to obtain the raw data at that time. Additionally, Nannungi et al and Linnemayr et al also document the impact of ART over time.

\section{Primary outcome: RTW}

\section{6 months after ART initiation}

Participants who initiated ART worked 11.95 hours (95\% CI 6.75 to 17.15 ) more per week than the average of the HIV+ cohort of ART and pre-ART persons, which was 3.7 hours (Analysis 2.2, Thirumurthy 2011)

Nannungi 2013 reported that of those on ART not working at baseline $(n=88), 50.9 \%$ returned to work $(n=45)$. Of the preART group unemployed at baseline $(\mathrm{n}=57), 48.8 \%$ were at work at 6 months $(\mathrm{n}=28)$.

Of those on ART working at baseline $(\mathrm{n}=169), 81.4 \%$ were still working at 6 months $(\mathrm{n}=138)$. In the pre-ART group, of those working at baseline $(\mathrm{n}=168), 84.5 \%$ were still employed at 6 months $(\mathrm{n}=142)(\mathrm{P}$ value $=0.000)$. Overall, $53 \%$ of those on ART ( $n=136$ ) were working compared to $47 \%$ of those in the pre-ART group $(n=106)$ at 6 months. However, the pre-ART group had more favorable predictive factors.

\section{2 to 24 months after ART initiation}

Long-term follow-up indicated a 12.1-hour (95\% CI 6.99 to 17.21) increase in hours worked per week at the end of 24 months for the baseline ART group compared to the average of the cohort which was 21 hours (Analysis 2.2, Thirumurthy 2011).

Nannungi 2013 reported continued improvement in employment status at 12 months after ART intitiation; of those on ART and not working at baseline $(\mathrm{n}=88), 55.6 \%$ had returned to work $(\mathrm{n}=49)$. Of those in the pre-ART group unemployed at baseline $(\mathrm{n}=57), 50.0 \%$ had RTW at 12 months $(\mathrm{n}=29)$. However, the pre-ART group had strong predictive characteristics for regaining employment compared to ART group. 
Of those on ART working at baseline ( $\mathrm{n}=169), 87.7 \%$ were still working at 12 months $(\mathrm{n}=148)$. In the pre-ART group, of the $74.5 \%$ working at baseline $(n=168), 75 \%$ were still employed at 12 months $(\mathrm{n}=126)$.

Overall, $46 \%$ of those on ART ( $n=118$ ) were working compared to $54 \%$ of those in the pre-ART group $(\mathrm{n}=121)$ at 12 months. However, the pre-ART group had more males, better physical health functioning and higher CD4 count, which are the strongest predictors of employment. After adjusting for gender, age, physical health functioning, education, relationship status and CD4 count, the ART group was more likely to be employed than the pre-ART group (OR 1.56, 95\% CI 1.15 to 2.12 ) at 12 months folllow up. Linnemayr 2013 found a greater likelihood of employment for the ART group compared to the pre-ART group (OR 1.88, 95\% CI 1.47 to 2.41 ) at 12 months follow-up.

The meta-analysis for Linnemayr 2013 and Nannungi 2013 found an increased likelihood of employment for those on ART (OR 1.75 , 95\% CI 1.44 to 2.12 ) Analysis 2.1 .

\section{Vocational interventions}

\section{Vocational therapy versus no vocational therapy}

\section{Primary outcome: RTW}

Martin 2012 measured outcomes at 6-month intervals beginning at baseline and continuing at $6,12,18$, and 24 months, however the authors did not report these follow-up results, only providing a table of "estimated transition rates" in and out of employment based on a Markov model for the outcomes. We requested further information, but the authors did not provide it.

\section{Grading of the evidence}

We used the GRADE approach to assess the quality of the evidence. All three observational studies, that is Bor 2012, Larson 2013, and Thirumurthy 2011, started with a low-quality evidence rating, and the RCT, that is Martin 2012, began at high rating as prescribed by the GRADE approach protocol (see Table 1).

\section{HIV+ persons utilizing ART versus healthy participants}

We rated the evidence in this comparison to be very low quality. We downgraded the quality of evidence based on a high risk of bias due to limitations in study design and implementation. We did not downgrade the quality of the evidence due to indirectness because we judged there to be no limitations due to the use of direct populations, comparable interventions with similar control groups, and no use of surrogate data. Unexplained heterogeneity or inconsistency in the results showed no limitations for further downgrading of the evidence. We downgraded the quality of the evidence further based on imprecision, which was due to wide confidence intervals in both studies. We did not find evidence to downgrade for publication bias.

We found no justification for upgrading the quality of evidence. The magnitude of effect was not large, there was no dose-effect relation, and the studies did not exclude all confounding.

\section{HIV+ persons utilizing ART versus HIV+ persons pre-ART}

We graded the quality of evidence for this comparison as very low. We found no reason to downgrade the quality of evidence because of problems in allocation concealment and blinding. We downgraded the quality of evidence for limitations in study design implementation due risk of bias for baseline comparability, lack of adjustment for confounding and incomplete attrition data. We did not find any reason to downgrade for the indirectness of the evidence in this comparison. We found no sign of indirect evidence or use of surrogate data in any study. There was no reason to downgrade the quality of the evidence based on unexplained heterogeneity or inconsistency in the results or for publication bias. We found no justification for upgrading the quality of evidence. The magnitude of effect was not large, there was no dose-effect relation, and the studies did not exclude all confounding.

\section{Vocational therapy versus no vocational therapy}

We graded the quality of evidence for this comparison as very low. We downgraded the quality of evidence based on limitations in study design and implementation, as the study had a high risk of bias due to a lack of reporting of allocation concealment and loss to follow-up. Furthermore, the study was unblinded and the use of selective reporting necessitated another downgrade of the quality of evidence. We also downgraded the quality of the evidence for indirectness of the evidence. The authors did not report any follow-up data. As only a single study provided evidence for this comparison, there was no need to downgrade the quality of the evidence because of unexplained heterogeneity or inconsistency in the results or because of publication bias. However, imprecision of the results in the form of complicated, unjustified statistical analysis of unclear outcomes necessitated downgrading the quality of the evidence further.

\section{DISCUSSION}

\section{Summary of main results}

We found very low-quality evidence in five studies that ART for $\mathrm{HIV}+$ persons improves ability to work and maintain employment. 
The magnitude of the intervention effect is unclear due to different results between comparisons (HIV+ vs. Healthy; HIV+ on ART vs. HIV+ pre-ART). The studies indicated that ART does not fully restore work capacity in HIV+ persons compared to healthy individuals. Two years after the start of ART, HIV+ persons still worked fewer days than healthy people. Five years after the start of ART there was a $27 \%$ greater unemployment rate among HIV+ people. However, the studies comparing HIV+ persons on ART with $\mathrm{HIV}+$ persons not yet on ART, indicate that ART receipents are almost twice as likely to be employed than HIV+ persons preART.

Based on two studies conducted with 33,379 participants (Bor 2012; Larson 2013), we found very low-quality evidence showing that HIV+ people utilizing ART worked less prior to ART initiation and got increasingly employed after ART initiation. Although employment increased after ART initiation, neither study showed full recovery of employment for the HIV+ index group in comparison to the healthy reference group during the follow-up period.

Two studies showed a similar trend in outcomes over a four-year period (Bor 2012; Larson 2013). There was no statistical difference at 24 months pre-ART initiation between the HIV+ persons' index group and the healthy participants' control group. However, for the HIV+ persons, likelihood of employment and number of days worked per month declined significantly by six months prior to the start of ART. At the start of ART, unemployment in HIV+ persons was high in comparison to the healthy reference group. Larson 2013 reported that employment outcomes improved six months after ART initiation and continued to increase at 18 to 24 months after the start of ART. Although there was improvement, neither Bor 2012 nor Larson 2013 indicated a full recovery of employment outcomes by the HIV+ persons on ART. The rate of improvement varied between the two studies. At 18 to 24 months post-ART initiation, Larson 2013 reported that HIV+ persons worked approximately one day less than healthy participants. However, at 18 to 24 months post-ART initiation, Bor 2012 reported a likelihood of employment for HIV+ persons on ART as less than half that of the healthy reference group. Bor 2012 reported statistically significant differences between the employment outcomes of the index group and those of the reference group until 36 to 60 months post-ART initiation. The differences between the results of the two studies can be partially accounted for by their use of different outcome measures. The Larson 2013 study used number of days worked, which notes smaller improvements in labor outcomes, whereas the Bor 2012 study used absolute outcomes of employed/unemployed, which prevented the intervention from showing smaller increases in labor productivity. Linnemayr 2013 and Nannungi 2013 both reported improved RTW outcomes in HIV + persons on ART in Uganda over a 12month period. At baseline, the ART group had higher unemployment than the pre-ART group. Both studies indicated the most significant improvement in employment outcomes in the first 6 months for HIV+ persons on ART. Similiar to the findings of Bor 2012 and Larson 2013, the number of those employed continued to rise after 12 months on ART, although not as dramatically as in the first 6 months. Half of those who were unemployed at baseline returned to work at six months in both the ART and pre-ART groups in one study (Nannungi 2013). Although, it is important to note that the characteristics of the pre-ART group were more favorable to employment, due to a higher number of males and better overall health. Thereby, underestimating the overall effect of the intervention. When the analysis was adjusted for gender and health status, the likelihood of being employed favored the ART group. Of those who were employed at baseline, a larger percentage of the ART group remained employed at 12 months follow-up than in the pre-ART group. The meta-analysis indicated a higher likelihood of employment in the ART group when considering the impact of ART over time (Linnemayr 2013; Nannungi 2013). Thirumurthy 2011 measured employment outcomes in hours worked per week, indicating improvement in employment outcomes after ART initiation over HIV+ people who were pre-ART. The results indicate an intervention effect for ART improving the number of hours worked per week. In the analysis, the combined group of those on ART and those pre-ART worked an average of 21 hours per week, where the ART group alone worked approximately 32 hours per week up to 24 months follow-up.

From the Bor 2012 and Larson 2013 studies, we know that without ART, unemployment rises considerably. Apart from ART, no other factors have been identified within the literature to support the increased labor productivity findings and employment outcomes of Linnemayr 2013, Nannungi 2013, and Thirumurthy 2011.

Martin 2012 found no evidence of the effectiveness of vocational rehabilitation interventions. As our systematic search yielded no studies on psychological interventions, we cannot say if they help or not.

\section{Overall completeness and applicability of evidence}

The importance of interventions to help HIV+ persons to return to work has been highly stressed. However, surprisingly few intervention studies have been conducted in this area.

The studies we found had been conducted in countries with a high prevalence of HIV, that is South Africa, Kenya, and Uganda, as well as in countries with a lower prevalence of HIV, that is India and the United States. There were no studies from Europe, Latin America, or Australia. Given the differences in social security legislation, it is unclear if the evidence applies to European countries.

Furthermore, evidence from one study suggested that ART interventions conducted in rural settings show a stronger effect. This might be due to accessibility of employment for farmers who are self-employed or working in the informal sector, whereas urban participants may have greater difficulty reaccessing previous employment, particularly in areas with higher formal-sector devel- 
opment (Linnemayr 2013). Of the five included pharmacological studies, only one study, Linnemayr 2013, identified rural participants from urban participants and analyzed the data separately. Two other studies identified mixed urban and rural residency among participant demographics, but did not perform subgroup analysis on the data (Bor 2012; Rosen 2010). Nannungi 2013 used data from urban clinics. Larson 2013 focused exclusively on tea plantation workers and therefore must be considered separately, as all the participants worked for the same employer. The lack of subgroup analysis between rural and urban groups hindered applicability of the evidence across different socioeconomic and geographical locations. Part and parcel of the rural versus urban issue, the nature of employment - that is, whether formal or informal - is not consistently distinguished throughout the studies, which may also contribute to a lack of applicability of the evidence by not providing a full picture of the effect of ART on different careers and their RTW outcomes.

Research suggests that women are at higher risk of unemployment overall than men. Dray-Spira 2006 highlighted the disproportionate loss of employment for women. In this review, only the study by Thirumurthy 2011 supports this finding. Three studies stratified outcome data by gender (Larson 2013; Linnemayr 2013; Thirumurthy 2011); however, the studies yielded conflicting results and were unable to fully account for the differences between sexes. Larson 2013 and Linnemayr 2013 reported potentially better employment outcomes for women. Larson 2013 suggested that women's improved employment outcomes could be due to the increased likelihood of transfer to less physically demanding work. However, the statistically nonsignificant findings for males in the Linnemayr 2013 study could be due to the small male sample size and therefore insufficent power to detect the actual effect. In contrast, Thirumurthy 2011 reported better employment outcomes for males. Thirumurthy 2011 hypothesized that discrimination among the sexes segregates employment opportunities in the KwaZulu-Natal Umkhanyakude District, and these differences could play a role in HIV+ peoples' ability to maintain or return to employment. Therefore, the gender component of RTW outcomes needs further exploration. Interventions need to be tailored to suit the needs of each sex, confounding for different societal, cultural, economic, and physical factors specific to each gender within a specified population. The lack of these adjustments may diminish the confidence in the intervention effect.

Unfortunately, we could not include all potentially relevant studies in this review. Baran 2012 examined multiple ART therapies in relation to healthcare costs and economic productivity for employers. This data could contribute to understanding the cost-effectiveness of ART programs as a secondary outcome. However, AbbVie Pharmaceutical Group funded the study and would not approve the release of necessary unpublished data for our use. The study examined three different types of ART medications, highlighting the differences in outcomes for participants based on the specific ART medication combination they received (Baran
2012). None of the pharmacological interventions in this review accounted for differences in medication combinations. Had researchers of the ART studies conducted subgroup analysis, intervention effects could have been associated with specific treatment regimens. Although the HIV+ participants were drawn from a single geographic area or treatment center where a specific ART medication combination may be most common, there is no evidence to indicate that participants received the same ART medication combinations or regimens. Therefore, research in regards to specific ART medication combinations, such as in the Baran 2012 study, could have shown differences in employment outcomes based on different ART medication combinations. In addition, we excluded a non-intervention, modeling study that examined the secondary outcome of cost-effectiveness of ART programs by comparing estimated total program costs with select economic benefits of ART. This study by Resch 2011 examined 1. restored labor productivity among workers with AIDS, 2. orphan care expenditures avoided because of parent survival due to ART, and 3. delayed end-oflife care costs associated with AIDS-related death. Resch 2011 reported an estimated expenditure of USD 14.2 billion for ART from 2011 to 2020 for the South African cohort of 3.5 million people. The study estimated a return on investment of USD 12 billion to USD 34 billion through improved labor productivity, averted orphan care expenses, and deferred medical treatment for end-of-life care and opportunistic infections.

One other prospective cohort study, that produced three-year and five-year follow-up publications, Rosen 2010 and Rosen 2014, examined the economic well-being of ART patients in South Africa. We excluded the study as it did not meet our inclusion criteria due to the lack of a control group. However, the findings showed a continued increase in employment from $32 \%$ to $44 \%$ between the start of ART and the five-year follow-up. These findings support the findings in all five included CBA ART studies (Bor 2012; Larson 2013; Linnemayr 2013; Nannungi 2013; Thirumurthy 2011). Of the 248 participants who were unemployed but looking for work at baseline, 39\% ( $\mathrm{n}=96) \mathrm{RTW}$, and of the 96 participants who were unemployed at baseline and not seeking work, 30\% ( $\mathrm{n}=$ 29) RTW and 53\% ( $\mathrm{n}=51)$ were actively seeking employment at the end of follow-up. Furthermore, the study examined outcomes outside of our predetermined outcomes, including the probability of experiencing pain or fatigue in the last week, the probability of being able to perform normal activities over the previous fiveday work week, and reliance on external support in the form of a caretaker. The data collected demonstrated a decrease in reporting pain in the previous week from $69 \%$ at baseline to $17 \%$ (P value less than 0.001 ) and a decrease in reporting fatigue in the previous week from $62 \%$ at baseline to $7 \%$ (P value less than 0.001 ) after five years. These health improvements coincide with findings by Larson 2013, where the measure of number of days worked allowed for smaller improvements in labor outcomes to be noted. Therefore, reductions in pain and fatigue due to ART may incrementally improve a person's capacity to work. 
The three included ART studies examined strict dichotomous outcomes of employment or unemployment (Bor 2012; Linnemayr 2013; Nannungi 2013), whereas the other two ART studies examined reduction in the labor productivity of $\mathrm{HIV}+$ persons without a definitive loss of employment or re-employment (Larson 2013; Thirumurthy 2011). The overall evidence did not account for specific reasons of unemployment but assumes loss of employment is solely attributable to HIV status. Therefore, a pharmacological intervention targeting loss of employment due to HIV would not produce the same effect on RTW outcomes for HIV+ persons who lost their job for other reasons.

Two included studies evaluated the effects of CD4 counts or progression of the disease at initiation of the intervention (Linnemayr 2013; Nannungi 2013). Although the index group criteria in the Thirumurthy 2011 study required participants to a have a CD4 count less than 200 , the analysis did not take into account varying levels of health status. Along the same vein, not all of the studies clearly distinguished HIV+ participants from participants with fully developed AIDS. Only two studies clearly indicated the use of World Health Organization (WHO) guidelines for diagnosis of HIV/AIDS and ART eligibility (Linnemayr 2013; Nannungi 2013). The differing levels of health status, by either CD4 counts or HIV versus AIDS, at initiation of the intervention could impact the outcomes.

In 2012, the WHO reported varying levels of HIV prevalence in working-age populations (15 to 49 years) among the countries examined in the pharmacological ART intervention studies: South Africa (17.9\%), Kenya (6.1\%), Uganda (7.4\%), and India (0.3\%) (WHO 2013a; WHO 2013b; WHO 2013c; WHO $2013 \mathrm{~d}$ ). Within these countries, the overall makeup of the HIV+ population varies. These statistics indicate diverse social and political environments for HIV within each population. ART coverage among HIV+ persons also varies between countries: South Africa (80\%), Kenya (73\%), Uganda (64\%), and India (50\%). Therefore, the ART environment, available knowledge, access to other HIV services, and individual perceptions may also influence employment outcomes within a specific population. The cultural, social, educational, political, and economic diversity of each of the countries included in this review should be considered when examining the effectiveness of the interventions by their location. Furthermore, none of the studies controlled for possible co-occurring interventions, which may have positively altered the intervention effect.

\section{Quality of the evidence}

\section{Pharmacological interventions}

\author{
HIV+ persons utilizing ART versus healthy (non-HIV+) \\ individuals
}

We rated the evidence in this comparison that includes two studies (Bor 2012; Larson 2013) to be very low quality. We downgraded the quality of evidence based on a high risk of bias due to limitations in study design and implementation. We did not downgrade the quality of the evidence due to indirectness because we judged there to be no limitations due to the use of direct populations, comparable interventions with similar control groups, and no use of surrogate data. Unexplained heterogeneity or inconsistency in the results showed no limitations for further downgrading of the evidence. We downgraded the quality of the evidence further based on imprecision, which was due to wide confidence intervals in both studies. We did not find evidence to downgrade for publication bias.

We found no justification for upgrading the quality of evidence. The magnitude of effect was not large, there was no dose-effect relation, and the studies did not exclude all confounding.

\section{HIV+ persons utilizing ART versus HIV+ persons pre-ART}

We graded the quality of evidence for this comparison that includes three studies (Linnemayr 2013; Nannungi 2013; Thirumurthy 2011) as very low. We found no reason to downgrade the quality of evidence because of problems in allocation concealment and blinding. We downgraded the quality of evidence for limitations in study design implementation due risk of bias for baseline comparability, lack of adjustment for confounding and incomplete attrition data. We did not find any reason to downgrade for the indirectness of the evidence in this comparison. We found no sign of indirect evidence or use of surrogate data in any study. There was no reason to downgrade the quality of the evidence based on unexplained heterogeneity or inconsistency in the results or for publication bias.

We found no justification for upgrading the quality of evidence. The magnitude of effect was not large, there was no dose-effect relation, and the studies did not exclude all confounding.

\section{Vocational interventions}

\section{HIV+ persons utilizing vocational therapy versus HIV+ persons not utilizing vocational therapy}

We graded the quality of evidence for this comparison that includes just one study (Martin 2012) as very low. We downgraded the quality of evidence based on limitations in study design and implementation, as the study had a high risk of bias due to a lack of reporting of allocation concealment and loss to follow-up. Furthermore, the study was unblinded and the use of selective reporting necessitated another downgrade of the quality of evidence. We also downgraded the quality of the evidence for indirectness of the evidence. The authors did not report any follow-up data. As only a single study provided evidence for this comparison, there was no 
need to downgrade the quality of the evidence because of unexplained heterogeneity or inconsistency in the results or because of publication bias. However, imprecision of the results in the form of complicated, unjustified statistical analysis of unclear outcomes necessitated downgrading the quality of the evidence further.

\section{Potential biases in the review process}

We allowed the inclusion of studies with unemployed participants at time of intervention initiation (Bor 2012; Linnemayr 2013; Nannungi 2013; Thirumurthy 2011), which required relaxing our predetermined inclusion criteria. This decision may have potentially influenced the results.

Language bias is not a problem in this review, as we excluded no studies on the basis of publication language.

\section{Agreements and disagreements with other studies or reviews}

To our knowledge, this is the first systematic review to analyze the effects of interventions designed to improve employment outcomes for HIV+ persons.

\section{AUTHORS'CONCLUSIONS}

\section{Implications for practice}

We found very low-quality evidence for an increase in days worked and employment rates among HIV+ people who where started on ART compared to healthy people to a level only a little under that of healthy workers. Additionally, we found very low-quality evidence for improvement in RTW outcomes for HIV+ persons on ART compared to HIV+ persons who are pre-ART. There was no evidence of the effectiveness of vocational rehabilitation. No studies assessed the effectiveness of psychological or other interventions.

\section{Implications for research}

Further research is required and should include more RCTs of vocational, psychological, educational, and support interventions. Researchers should account for all possible influences on employment outcomes, such as co-occurring interventions available within a treatment population. To improve the quality of the evidence, studies should fully report predetermined outcomes as well as account and compensate for attrition. All possible confounders (gender, age, socioeconomic status, migration, and disease severity) should be analyzed. Researchers should focus specifically on differences in employment outcomes by gender to help fine-tune the potency of interventions. Future pharmacological studies should clarify ART therapy regimens and differentiate between cART (combination antiretroviral therapy) prescriptions.

\section{RCTs}

More RCTs would improve the quality of evidence. Although the RCT study design is ideal for showing effectiveness, it is an unethical approach to conducting pharmacological ART interventions. However, RCTs can be effectively utilized for vocational and psychological interventions. Given the probably modest effect sizes and a large risk of confounding, RCTs with a follow-up of at least one year would be ideal.

\section{CBA studies}

CBA studies present a solution to the problem of studying ART interventions. Future studies should aim to overcome the risk of bias issues we identified in the studies we included in this review.

\section{Blinding}

All future studies should ensure blinding of outcome assessors, even if blinding of participants and personnel is not possible.

\section{Other interventions}

Although our comprehensive search criteria yielded only five pharmacological ART interventions and one mixed vocational and psychological counseling intervention, many other intervention possibilities exist. For example, income support interventions could possibly reduce the stress related to financial burden. Financial security may improve well-being and quality of life, whereas stress may potentially lead to expedited disease progression followed by job loss. Researchers could explore job or career field-specific intervention programs that focus on meeting the specific needs of the employee within the given profession. It is reasonable to assume that involvement in meaningful work improves one's sense of self worth in addition to providing many other benefits. Caretaker or family educational interventions might encourage RTW by dispelling the myth that HIV+ people should not work and must play the 'sick role'. Educational interventions for caretakers or family could furthermore enhance the support system of the HIV+ individual, thereby boosting RTW outcomes. Educational interventions for employers could assist companies in mindfully accommodating HIV + employees, retaining HIV + employees, and decreasing absenteeism. The aforementioned list is not exhaustive of potential interventions, but merely highlights the most obvious gaps in current knowledge.

\section{Reporting}

All of the studies in our review indicated a high risk of bias due to incomplete outcome data and selective reporting. Future studies should employ all appropriate methods to reduce risk of bias, thereby improving the quality of evidence. 


\section{ACKNOWLEDG EMENTS}

We would like to thank Cochrane Work Trials Search Co-ordinators Leena Isotalo and Kaisa Neuvonen for developing the search strategy and Managing Editor Jani Ruotsalainen and Co-ordinating Editor Jos Verbeek for editing the text and providing helpful comments. We would also like to thank Richard Othieno for his contributions to the protocol.

\section{RE FER E N C E S}

\section{References to studies included in this review}

Bor 2012 \{published data only\}

Bor J, Tanser F, Newell ML, Baringhausen T. In a study of a population cohort in South Africa, HIV patients on antiretrovirals had nearly full recovery of employment. Health Affairs (Millwood) 2012;31(7):1459-69.

Larson 2013 \{published data only\}

Larson BA, Fox MP, Bii M, Rosen S, Rohr J, Shaffer D, et al. Antiretroviral therapy, labor productivity, and sex: a longitudinal cohort study of tea pluckers in Kenya. AIDS 2012;27(1):115-23.

Linnemayr 2013 \{published data only\} Linnemayr S, Glick P, Kityo C, Mugyeni P, Wagner G. Prospective cohort study of the impact of antiretroviral therapy on employment outcomes among HIV clients in Uganda. AIDS Patient Care and STDs 2013;27(12): 707-14. [DOI: 10.1089/apc.2013.0139]

Martin 2012 \{published data only (unpublished sought but not used)\} Martin DJ, Chernoff RA, Buitron M, Comulada WS, Liang LJ, Wong FL. Helping people with HIV/AIDS return to work: a randomized clinical trial. Rehabilitation Psychology 2012;57(4):280-90.

Nannungi 2013 \{published data only\}

Nannungi A, Wagner G, Ghosh-Dastidar B. The impact of ART on the economic outcomes of people living with HIV/ AIDS. AIDS Research and Treatment 2013;2013(362972): $1-7$.

Thirumurthy 2011 \{published data only\} Thirumurthy H, Jafri A, Srinivas G, Arumugam V, Saravanan RM, Angappan SK, et al. Two-year impacts on employment and income among adults receiving antiretroviral therapy in Tamil Nadu, India: a cohort study. AIDS 2011;25(2):239-46.

\section{References to studies excluded from this review}

Ajithkumar 2007 \{published data only\}

Ajithkumar K, Iype T, Arun J, Ajitha B, Aveenlal K, Antony T. Impact of antiretroviral therapy on vocational rehabilitation. AIDS Care 2007;19(10):1310-2. [DOI: 10.1080/09540120701408902]

Bernell 2005 \{published data only\} Bernell SL, Shinogle JA. The relationship between HAART use and employment for HIV-positive individuals: an empirical analysis and policy outlook. Health Policy 2005; 71(2):255-64. [DOI: 10.1016/j.healthpol.2004.08.012]

Escovitz 2005 \{published data only\}

Escovitz K, Donegan K. Providing effective employment supports for persons living with HIV: The KEEP project. Journal of Vocational Rehabilitation 2005;22:105-14.

Goldman 2004 \{published data only\} Goldman DP, Bao Y. Effective HIV treatment and the employment of $\mathrm{HIV}(+)$ adults. Health Services Research 2004;39(6.1):1691-712.

Herdt 1999 \{published data only\}

Herdt J, Bengel J, Bührlen-Armstrong B. Multiplier Approaches in AIDS-Prevention - Part 2.E valuation of a Training Program of the German Federal Center for Health Education [Multiplikatorenkonzepte in der AIDSPrävention Teil 2: Evaluation eines Trainingsprogramms der Bundeszentrale fü r gesundheitliche Aufklärung].

Zeitschrift fü $r$ Gesundheitswissenschaften 1999;7:14-29.

Hergenrather 2013 \{published data only\} Hergenrather K, Geishecker S, Clark G, Rhodes S. A pilot test of the HOPE Intervention to explore employment and mental health among African American gay men living with HIV/AIDS: Results from a CBPR Study. AIDS Education and Prevention 2013;25(5):405-22.

Lee 2005 \{published data only (unpublished sought but not used)\} Lee RKY, Chan CCH. Factors affecting vocational outcomes of people with chronic illness participating in a supported competitive open employment program in Hong Kong. Work 2005;25(4):359-68.

Martin 2003 \{published data only\} Martin D, Brooks R, Ortiz D, Veniegas R. Perceived employment barriers and their relation to workforceentry intent among people with HIV/AIDS. Journal of Occupational Health Psychology 2003;8(3):181-94. [DOI: 10.1037/1076-8998.8.3.181]

Martin 2005 \{published data only (unpublished sought but not used)\} Martin DJ, Chernoff RA, Buitron M. Tailoring a vocational rehabilitation program to the needs of people with HIV/ AIDS: The Harbor-UCLA experience. Journal of Vocational Rehabilitation 2005;22(2):95-103. 
Maticka-Tyndale 2002 \{published data only\}

Maticka-Tyndale E, Adam BD, Cohen JJ. To work or not to work: combination therapies and HIV. Qualitative Health Research 2002;2013:362972. [DOI: 10.1155/2013/ 362972]

Resch 2011 \{published data only\}

Resch S, Korenromp E, Stover J, Blakely M, Krubiner $\mathrm{C}$, Thorien $\mathrm{K}$, et al. Economic returns to investment in AIDS treatment in low and middle income countries. PLoS ONE 2011;6(10):e25310. [DOI: 10.1371/ journal.pone.0025310]

Rosen 2004 \{published data only\}

Rosen S, Vincent J, MacLeoda W, Fox M, Theaa D, Simona J. The cost of HIV/AIDS to businesses in southern Africa. AIDS 2004;18:317-24. [DOI: 10.1097/ 01.aids.0000104361.21567.5f]

Rosen 2010 \{published data only\}

Rosen S, Larson B, Brennan A, Long L, Fox M, Mongwenyana $\mathrm{C}$, et al. Economic outcomes of patients receiving antiretroviral therapy for HIV/AIDS in South Africa are sustained through three years on treatment. PLoS ONE 2010;5(9):e12731. [DOI: 10.1371/ journal.pone.0012731]

Rosen 2014 \{published data only\}

Rosen S, Larson B, Rohr J, Sanne I, Mongwenyana C, Brennan A, et al. Effect of antiretroviral therapy on patients' economic well being: five-year follow-up. AIDS 2014;28: $417-24$.

Rosolen 2002 \{published data only\}

Rosolen D. Returning to work when you're HIV positive. Benefits Canada 2002;26(5):57-9.

Rueda 2012 \{published data only\}

Rueda S, Chambers L, Wilson M, Mustard C, Rourke SB, Bayoumi A, et al. Association of returning to work with better health in working-aged adults: a systematic review. American Journal of Public Health 2012;102(3):541-56.

Thirumurthy 2013 \{published data only\}

Thirumurthy H, Chamie G, Jain V, Kabami J, Kwarisiima $\mathrm{D}$, Clark T, et al. the SEARCH Collaboration. Improved employment and education outcomes in households of HIV-infected adults with high CD4 counts: evidence from a community health campaign in Uganda. AIDS 2013;27 (4):na. [DOI: 10.1097/QAD.0b013e32835c54d8]

Van der Borght 2006 \{published data only\} Van der Borght S, Rinke de Wit TF, Janssens V, Schim van der Loeff M, Rijckborst H, Lange JMA. HAART for the HIV-infected employees of large companies in Africa. The Lancet 2006;368:547-50.

Van der Borght 2010 \{published data only\}

Van der Borght SF, Schim van der Loeff MF, Clevenbergh P, Kabarega JP, Kamo E, van Cranenburgh K, et al. Long-term voluntary counseling and testing (VCT) uptake dynamics in a multi-country HIV workplace program in sub-Saharan Africa. AIDS Care 2010;22(2):195-205.

\section{References to studies awaiting assessment}

\section{Baran 2012 \{published and unpublished data\}}

Baran RW, Brook R, Kleinman N, Beren I, Dietz B. Employees living with human immunodeficiency virus: Impact of disease and antiretroviral therapies on health care costs and productivity. Journal of Managed Care Pharmacy 18;2:174.

Borwein 2010 \{published data only\} Borwein A, Chan K, Parashar S, Druyts E, Palmer AK, Montaner JS, et al. Overcoming employment barriers: Health and financial worries among a cohort of HIV positive individuals on HAART. Canadian Journal of Infectious Diseases and Medical Microbiology 2010;21(3): $84 \mathrm{~B}$.

Paul-Ward 2005 \{published data only (unpublished sought but not used)\}

Paul-Ward A, Braveman B, Kielhofner G, Levin M. Developing employment services for individuals with HIV/ AIDS: Participatory action strategies at work. Journal of Vocational Rehabilitation 2005;22(2):85-93.

Popiel 2010 \{published data only\}

Popiel M. HIV, employment and human rights in Canada: A workshop evaluation. Canadian Journal of Infectious Diseases and Medical Microbiology 2010;21(3):83B.

\section{Additional references}

\section{Blalock 2002}

Blalock AC, Mc Daniel JS, Farber EW. Effect of employment on quality of life and psychological functioning in patients with HIV/AIDS. Psychosomatics 2002;43:400-4.

Braveman 2006

Braveman B, Levin M, Kielhofner G. HIV/AIDS and return to work: A literature review one decade postintroduction of combination therapy (HAART). Work: $A$ Journal of Prevention, Assessment \& Rehabilitation 2006;27 (3):295-303.

\section{Campbell 2001}

Campbell MK, Mollison J, Grimshaw JM. Cluster trials in implementation research: estimation of intra-cluster correlation coefficients and sample size. Statistics in Medicine 2001;20(3):391-9.

Cho 2000

Cho BK, Rosenfeldt F, Turina MI, Karp RB, Ferguson TB, Bodnar E, et al. Joint statement on redundant (duplicate) publication by the editors of the undersigned cardiothoracic journals. Annals of Thoracic Surgery 2000;69(2):663.

Conyers 2004

Conyers LM. The impact of vocational services and employment on people with HIV/AIDS. Work 2004;23(3): 205-14.

De Boer 2011

De Boer AGEM, Taskila T, Tamminga SJ, Frings-Dresen MHW, Feuerstein M, Verbeek JH. Interventions to enhance return-to-work for cancer patients. Cochrane Database of Systematic Reviews 2011, Issue 2. [DOI: 10.1002/ 14651858.CD007569.pub2] 


\section{Downs 1998}

Downs SH, Black N. The feasibility of creating a checklist for the assessment of the methodological quality both of randomised and non-randomised studies of healthcare interventions. Journal of Epidemiology and Community Health 1998;52:377-84.

Dray-Spira 2006

Dray-Spira R, Persoz A, Boufassa F, Gueguen A, Lert F, Allegre T, et al. Employment loss following HIV infection in the era of highly active antiretroviral therapies. European Journal of Public Health 2006;16(1):89-95.

Feeley 2004

Feeley F, Bukuluki P, Collier A, Fox MP. The Impact of HIV/AIDS on Productivity and Labor Costs in Two Ugandan Corporations. Project report. Center for International Health and Development Boston University School of Public Health and School of Social Work and Social Administration, Makerere University. 2004 Nov.

Fox 2004

Fox MP, Rosen S, MacLeod WB, Wasunna M, Bii M, Foglia G, et al. The impact of HIV/AIDS on labour productivity in Kenya. Tropical Medicine \& International Health 2004;9: 318-24.

Gorman 2009

Gorman AA, Foley JM, Ettenhofer ML, Hinkin CH, van Gorp WG. Functional consequences of HIV-associated neuropsychological impairment. Neuropsychology Review 2009;19:186-203.

Henderson 2005

Henderson M, Glozier N, Holland Elliott K. Long term sickness absence. BMJ 2005;330(7495):802-3.

Higgins 2011

Higgins JPT, Green S (editors). Cochrane Handbook for Systematic Reviews of Interventions. Version 5.1.0 [updated March 2011]. The Cochrane Collaboration, 2011. Available from www.cochrane-handbook.org.

\section{ILO 2001}

International Labour Organisation. The ILO Code of Practice on HIV/AIDS and the World of Work. ILO Geneva 2001.

ILO 2010

International Labour Organisation. Recommendation Concerning HIV and AIDS and the World of Work. ILO Geneva 2010, issue No. 200.

Kaiser Family Foundation 2007

The Henry J. Kaiser Family Foundation. The Multisectoral Impact of the HIV/AIDS Epidemic - A Primer. Kaiser Family Foundation 2007.

Kelly 1998

Kelly B, Raphael B, Judd F, Perdices M, Kernutt G, Burnett $\mathrm{P}$, et al. Suicidal ideation, suicide attempts, and HIV infection. Psychosomatics 1998;34:405-15.

Kielhofner 2004

Kielhofner G, Braveman B, Finlayson M, Paul-Ward A, Goldbaum L, Goldstein K. Outcomes of a vocational program for people with AIDS. The American Journal of Occupational Therapy 2004;51:64-72.

Kohlenberg 2003

Kohlenberg B, Watts MW. Considering work for people living with HIV/AIDS: Evaluation of a group employment counselling program. Journal of Rehabilitation 2003;69: 22-9.

Linn 1985

Linn MW, Sandifer R, Stein S. Effects of unemployment on mental and physical health. American Journal of Public Health 1985;75(5):502-6.

\section{Rabkin 2004}

Rabkin JG, McElihiney M, Ferrando SJ, van Gorp WG, Hsing S. Predictors of employment of men with HIV/ AIDS: A longitudinal study. Psychosomatic Medicine 2004; 66:72-8.

\section{Rao 2008}

Rao D, Angell B, Lam C, Corrigan P. Stigma in the workplace: Employer attitudes about people with HIV in Beijing, Hong Kong, Chicago. Social Science \& Medicine 2008;67:1541-9.

\section{RevMan 2014}

The Nordic Cochrane Centre. The Cochrane Collaboration. Review Manager (RevMan). 5.3. Copenhagen: The Nordic Cochrane Centre. The Cochrane Collaboration, 2014.

\section{Rodger 2010}

Rodger AJ, Brecker N, Bhagani S, Fernandez T, Johnson M, Tookman A, et al. Attitudes and barriers to employment in HIV-positive patients. Occupational Medicine 2010;60: 423-9.

\section{Schaafsma 2010}

Schaafsma F, Schonstein E, Whelan KM, Ulvestad E, Kenny DT, Verbeek JH. Physical conditioning programs for improving work outcomes in workers with back pain. Cochrane Database of Systematic Reviews 2010, Issue 1. [DOI: 10.1002/14651858.CD001822.pub2]

\section{Sendi 2004}

Sendi P, Schellenberg F, Ungsedhapand C, Kaufmann GR, Bucher HC, Weber R, et al. Productivity costs and determinants of productivity in HIV-infected patients. Clinical Therapeutics 2004;26(5):791-800.

\section{Waddell 2006}

Waddell G, Burton AK. Is work good for your health and wellbeing?. Department for Work and Pensions, The Stationary Office, London 2006.

\section{WHO 2013a}

WHO. Kenya Statistics Summary (2002-present). http: //apps.who.int/gho/data/node.country.country-KEN (accessed 14 November 2014).

\section{WHO 2013b}

WHO. India Statistics Summary (2002-present). http: //apps.who.int/gho/data/node.country.country-IND (accessed 14 November 2014). 
WHO 2013c

WHO. South Africa Statistics Summary (2002-present). http://apps.who.int/gho/data/node.country.country-ZAF (accessed 14 November 2014).

WHO 2013d

WHO. Uganda Statistics Summary (2002-present). http:// apps.who.int/gho/data/node.country.country-UGA?lang= en (accessed 23 February 2015).

Yelin 1991

Yelin EH, Greenblatt RM, Hollander H, McMaster JR. The

impact of HIV-related illness on employment. American

Journal of Public Health 1991;81(1):79-84.

* Indicates the major publication for the study 


\section{CHARACTERISTICS OF STUDIES}

\section{Characteristics of included studies [ordered by study ID]}

\section{Bor 2012}

\begin{tabular}{ll}
\hline Methods & CBA study (retrospective) \\
\hline Participants & $\begin{array}{l}32,321 \text { population cohort of all working-age (18-59) people who were members of a } \\
\text { household in Africa Centre for Health and Population Studies's population surveillance } \\
\text { area during the } 10 \text {-year follow-up period, excluding HIV+ persons not accessing ART. } \\
\text { (South Africa) } \\
\text { Index group: } 2027 \text { HIV+ persons } \\
\text { Reference group: } 30,294\end{array}$ \\
\hline
\end{tabular}

Interventions

Intervention: Pharmacological, ART through the Hlabisa HIV Treatment and Care Program

Control: Drawn from the same population, but non-HIV, untreated, apparently healthy

\begin{tabular}{ll}
\hline Outcomes & $\begin{array}{l}\text { Employment: Employment status measured as 'yes' or 'no' } \\
\text { Authors also assessed: }\end{array}$ \\
& $\begin{array}{l}\text { 1) Unemployment due to illness, 2) Residence in surveillance area (migration indicator) } \\
\text {, 3) Physical function: Walk } 5 \mathrm{~km} \text { without stopping, carry heavy objects for } 20 \text { meters } \\
\text { without stopping, participate in vigorous activities, 4) Immunological status: CD4+ } \\
\text { lymphocyte counts }\end{array}$ \\
\hline Notes & ART \\
\hline
\end{tabular}

Risk of bias

\begin{tabular}{l|l|l}
\hline Bias & Authors' judgement & Support for judgement \\
\hline 14. Blinding (Subjects) & Low risk & $\begin{array}{l}\text { Retrospective data collected and cross-referenced from a } \\
\text { cohort's surveys of sociodemographics and health data. Par- } \\
\text { ticipants were unaware they were under investigation for } \\
\text { the specific intervention at the time of the cohort surveys }\end{array}$ \\
\hline 15. Blinding (outcome assessors) & Low risk & $\begin{array}{l}\text { Not blinded. Retrospective data collected and cross-refer- } \\
\text { enced from a cohort's surveys of sociodemographics and } \\
\text { health data. Objective outcomes that should have been un- } \\
\text { affected by blinding }\end{array}$ \\
\hline
\end{tabular}

16. Retrospective unplanned subgroup Unclear risk Retrospective study, data dredging not clear. analysis

17. Follow-up Low risk

Follow-ups conducted for both index and reference at 8-5 years, 5-3 years, 3-2.5 years, 2.5-2 years, 2-1.5 years, $1.5-1$ years, $1-0.5$ year both pre- and post-ART initiation

18. Statistical tests

Low risk

Odds ratio, t-statistics, and hazards ratio 
Bor 2012 (Continued)

\begin{tabular}{|c|c|c|}
\hline 19. Compliance & Unclear risk & $\begin{array}{l}\text { Compliance to ART was not monitored or insured. ART } \\
\text { adherence is required for survival, therefore compliance is } \\
\text { highly likely }\end{array}$ \\
\hline 20. Outcome measures & Low risk & $\begin{array}{l}\text { All predetermined outcome measures were analyzed and } \\
\text { reported }\end{array}$ \\
\hline 21. Selection Bias (population) & Low risk & $\begin{array}{l}\text { All participants were collected from South Africa's Africa } \\
\text { Centre population surveillance area in the Hlabisa subdis- } \\
\text { trict. The study used all HIV+ persons who were utiliz- } \\
\text { ing ART during the } 10 \text {-year follow-up period of the Africa } \\
\text { Centre's population surveillance study }\end{array}$ \\
\hline 22. Selection bias (time) & Low risk & $\begin{array}{l}\text { All individuals residing in the surveillance area were mon- } \\
\text { itored between } 2001-2010 \text { and for inclusion in the study } \\
\text { were required to have lived in the surveillance area } 6 \text { months } \\
\text { prior to the establishment of the Hlabisa HIV Treatment } \\
\text { and Care Program }\end{array}$ \\
\hline 23. Randomization & High risk & No randomization. Retrospective cohort study. \\
\hline 24. Allocation concealment & Unclear risk & $\begin{array}{l}\text { Retrospective study of a cohort. Participants were not as- } \\
\text { signed by the research team, but were predetermined by } \\
\text { health status. Did not report the use of adequate sequence } \\
\text { generation or allocation concealment techniques }\end{array}$ \\
\hline 25. Adjustment for confounding & High risk & $\begin{array}{l}\text { Migration confounder addressed. Gender differences not } \\
\text { addressed. Age differences not addressed. SES differences } \\
\text { not addressed. Disease severity not addressed }\end{array}$ \\
\hline 26. Incomplete outcome data & High risk & $\begin{array}{l}20.4 \% \text { attrition in index group addressed. No data reported } \\
\text { for control group }\end{array}$ \\
\hline Baseline comparability & High risk & $\begin{array}{l}\text { Differences in gender proportions: Index group } 80.1 \% \text { fe- } \\
\text { male and reference group } 59.9 \% \text { female } \\
\text { Age groups were disproportionate: (18-25 years) index } 17 \text {. } \\
5 \% \text {, reference } 49.4 \% \text {; ( } 25-34 \text { years) index } 38.7 \% \text {, reference } \\
21 \% \text {; ( } 35-44 \text { years) index } 31 \% \text {, reference } 18.2 \% \\
\text { SES not specifically reported, but > } 12 \text { years of school was } \\
\text { also disproportionate between groups: index } 33.9 \% \text {, refer- } \\
\text { ence } 45.1 \% \\
\text { Disease severity was incomparable in the index group } \\
\text { (HIV+ persons) and reference group (healthy and undiag- } \\
\text { nosed, asymptomatic HIV+ people) }\end{array}$ \\
\hline
\end{tabular}

Interventions for improving employment outcomes for workers with HIV (Review) 


\begin{tabular}{l|l}
\hline Methods & CBA study \\
\hline Participants & $\begin{array}{l}\text { Index: } 237 \text { HIV + tea pluckers with a CD4 count < 350 who began ART between 2004 } \\
\text { and } 2007 \\
\text { Control: Pool of workers from the 13,178 general work force population } \\
\text { (Kenya) }\end{array}$ \\
\hline Interventions & $\begin{array}{l}\text { Intervention: Pharmacological, ART } \\
\text { Control: Healthy, untreated general work force }\end{array}$ \\
\hline Outcomes & $\begin{array}{l}\text { Employment: } \\
1 . \text { Total days working per month } \\
\text { 2. Days spent plucking tea per month } \\
\text { 3. Total kg of tea harvested per month } \\
\text { 4. Total income per month }\end{array}$ \\
\hline Notes & HIV \\
\hline
\end{tabular}

\section{Risk of bias}

\section{Bias}

14. Blinding (Subjects)

15. Blinding (outcome assessors)

16. Retrospective unplanned subgroup Unclear risk analysis

\begin{tabular}{|c|c|c|}
\hline 17. Follow-up & Low risk & $\begin{array}{l}\text { Follow-ups conducted for both index and reference at } 6 \text {-month } \\
\text { intervals beginning } 24 \text { months pre-ART until } 24 \text { months post- } \\
\text { ART }\end{array}$ \\
\hline 18. Statistical tests & Low risk & Mean difference (95\% confidence interval) \\
\hline 19. Compliance & Unclear risk & $\begin{array}{l}\text { Compliance to ART was not monitored or insured. ART ad- } \\
\text { herence is required for survival, therefore compliance is highly } \\
\text { likely }\end{array}$ \\
\hline
\end{tabular}

20. Outcome measures

Low risk

Low risk

\section{Authors' judgement Support for judgement}

Low risk

Participants were unaware of intervention.

Not reported. Objective outcomes that should have been unaffected by blinding

Retrospective study, data dredging not clear.

Follow-ups conducted for both index and reference at 6-month intervals beginning 24 months pre-ART until 24 months post-

21. Selection Bias (population)
All predetermined outcome measures were analyzed and re- ported

Study used all HIV + persons who visited the tea plantation hospitals and healthcare clinics. All participants were employees of two tea plantations in the Kericho District of Kenya. However, it is important to note that some participants in the reference group were likely HIV+ but were undiagnosed or had not declared their HIV status as positive. This could have impacted 
Larson 2013 (Continued)

the results

\begin{tabular}{|c|c|c|}
\hline 22. Selection bias (time) & Low risk & All participants were monitored between 2006-2009. \\
\hline 23. Randomization & High risk & $\begin{array}{l}\text { No randomization for index group. Index group was matched } \\
\text { with four references who were randomized into subestate groups }\end{array}$ \\
\hline 24. Allocation concealment & Unclear risk & $\begin{array}{l}\text { Retrospective, non-randomized study. Did not report the use of } \\
\text { adequate sequence generation or allocation concealment tech- } \\
\text { niques }\end{array}$ \\
\hline
\end{tabular}

25. Adjustment for confounding High risk

Adjustment for gender outcome differences. Age differences not addressed. SES differences not addressed. Disease severity not addressed. Migration differences not addressed

26. Incomplete outcome data High risk

$6 \%$ attrition in index group addressed. No attrition data reported for controls. Data for workers in the general work force was incomplete due to a change in the management system resulting in the reassigning of employment identification numbers

Baseline comparability High risk

No baseline demographics were reported for the reference group. The index group mean age for women was 39.4 (27.4-53) and for men was 39.5 (24.9-54.4). The average years of experience for women was 8.2 (1-24) years and for men was 7.7 (0.5-23) years. Median baseline CD4 counts for women were 178 (91243) and for men were 153.3 (85-215)

Linnemayr 2013

Methods

Participants
Longitudinal, prospective cohort study (CBA study)

602 HIV + treatment-naive clients, 18 years of age or older, who were newly evaluated for ART from 2 Joint Clinical Research Centres in Kampala (urban) and Kakira (rural) , Uganda.

Index: $300 \mathrm{HIV}+$ people initiating ART with CD4 count $<250$ cells $/ \mathrm{mm}^{3}$ (WHO disease stage III or IV) and had a 'treatment supporter'

Control: $302 \mathrm{HIV}+$ people pre-ART with CD4 count $<400$ cells $/ \mathrm{mm}^{3}$

Interventions

All participants underwent structured interview concerning background characteristics, physical and mental health status, and economic outcomes. Health data abstracted from patient medical records. Assessments taken at 0 and 12 months

Index: ART provided by Joint Clinical Research Centre HIV Clinic, plus general HIV treatment

Control: General HIV treatment, no ART

Outcomes

Employment:

1. Work status in the week preceding interview

Other health-related economic outcomes: 
2. Health interference with work (binary indicator of perceived health effect on work)

3. Pain interference with work in last month (5-point scale from 'not at all' to 'extremely')

4. Work-related self efficacy (single visual analogue scale $0-10$ )

\begin{tabular}{|c|c|}
\hline Notes & $\begin{array}{l}\text { Rand Corporation (California, USA) } \\
\text { Joint Clinical Research Centre (Kampala, Uganda) } \\
\text { Funding: The Rockfeller Foundation, Grant No. HE007;PIGWagner } \\
\text { Participants received } 5000 \text { Uganda Shillings ( }- \text { USD 2.50) for completion of each inter- } \\
\text { view }\end{array}$ \\
\hline
\end{tabular}

\section{Risk of bias}

Bias Authors' judgement $\quad$ Support for judgement

14. Blinding (Subjects) Unclear risk

15. Blinding (outcome assessors) Low risk

18. Statistical tests

Low risk

analysis

17. Follow-up

Low risk

18. Statistical tests

19. Compliance

Unclear risk

Low risk
No blinding, however due to a dichotomous outcome of employed or unemployed in past 7 days, this should not have affected the results

No blinding, objective outcomes should have been unaffected by lack of outcome assessor blinding

No evidence of retrospective unplanned subgroup analysis.

Follow-ups conducted at 6 and 12 months in both index and reference groups. Approximately $5 \%$ loss to attrition

Two-tailed t-test, $\mathrm{Chi}^{2}$ test (has statistically low power when study has small sample size $(\mathrm{n}=602))$

Performed 2 sensitivity analyses:

1. Excluded control-group participants who began ART treatment but were kept in the control group due to intention-totreat study design analysis

2. Restricted control group to members of a similar health status

ART adherence is required for survival, therefore compliance, although not monitored, is highly likely. Eligibility for the index group required the HIV+ persons have a 'treatment supporter' for adherence ported. 
Linnemayr 2013 (Continued)

\begin{tabular}{|c|c|c|}
\hline 21. Selection Bias (population) & Unclear risk & $\begin{array}{l}\text { Eligible patients were approached by clinic } \\
\text { staff when ART eligibility was assessed. No } \\
\text { randomization. Intention-to-treat analysis } \\
\text { was utilized to avoid control-group mem- } \\
\text { bers changing to the index group }\end{array}$ \\
\hline 22. Selection bias (time) & Unclear risk & Recruitment timeline not specified. 2008? \\
\hline 23. Randomization & Unclear risk & $\begin{array}{l}\text { Non-randomized. Participants were prede- } \\
\text { termined to index and reference groups by } \\
\text { ART eligibility status }\end{array}$ \\
\hline 24. Allocation concealment & Unclear risk & $\begin{array}{l}\text { Non-randomized. Did not report the use of } \\
\text { adequate sequence generation or allocation } \\
\text { concealment techniques }\end{array}$ \\
\hline 25. Adjustment for confounding & Unclear risk & $\begin{array}{l}\text { Stratified data by gender and included } \\
\text { physical health and mental health con- } \\
\text { founders. Did not account for age, SES, or } \\
\text { education }\end{array}$ \\
\hline 26. Incomplete outcome data & Low risk & $\begin{array}{l}<5 \% \text { attrition, and all outcome data re- } \\
\text { ported. }\end{array}$ \\
\hline Baseline comparability & Unclear risk & $\begin{array}{l}\text { As expected, baseline health differences } \\
\text { were present between the index and ref- } \\
\text { erence groups due to disease progression } \\
\text { and need for treatment. However, authors } \\
\text { claim to have performed a sensitivity anal- } \\
\text { ysis and reported that the overall results did } \\
\text { not change. However, data was not pre- } \\
\text { sented in the publication }\end{array}$ \\
\hline
\end{tabular}

Martin 2012

\begin{tabular}{ll} 
Methods & RCT \\
\hline Participants & $\begin{array}{l}174 \text { HIV + persons aged 18-65 who had stopped working due to disability, were receiving } \\
\text { disability services, and who were contemplating rejoining the workforce. (USA) } \\
\text { Index group: } 83 \\
\text { Control group: } 91\end{array}$ \\
\hline Interventions & $\begin{array}{c}\text { Intervention: } \\
\bullet\end{array}$ \\
$\begin{array}{l}\text { end of the } 7 \text {-week group session period } \\
-13 \text { group sessions over a period of } 7 \text { weeks } \\
\text { Control: } \\
-1 \text { group session in which participants were given community referrals to assist in }\end{array}$
\end{tabular}

Interventions for improving employment outcomes for workers with HIV (Review)

Copyright (๑) 2015 The Cochrane Collaboration. Published by John Wiley \& Sons, Ltd. 
Martin 2012 (Continued)

returning to work

\begin{tabular}{l|l}
\hline Outcomes & Employment: \\
& 1. Full-time, part-time, temporary, or under-the-table paid employment in the past \\
& $\begin{array}{l}\text { 6 months and average hours per week } \\
\text { 2. Unpaid volunteer work in the past } 6 \text { months and average hours per week }\end{array}$ \\
& $\begin{array}{l}\text { 3. Attendance at job training classes in the past } 6 \text { months and average hours per week } \\
\text { 4. Active job search for a period of } 30 \text { days or longer in the past } 6 \text { months } \\
\text { Authors also assessed: } \\
\text { - Demographics in past } 6 \text { months } \\
\text { - Current health status }\end{array}$ \\
\hline Notes & Contacted authors for additional information. None provided. \\
\hline
\end{tabular}

\section{Risk of bias}

Bias

Authors' judgement Support for judgement

\begin{tabular}{lll} 
14. Blinding (Subjects) & High risk & No blinding of participants or personnel. \\
\hline 15. Blinding (outcome assessors) & High risk & Not reported.
\end{tabular}

16. Retrospective unplanned subgroup Unclear risk analysis

Only baseline data was reported. No follow-up outcomes provided

\begin{tabular}{l|l} 
17. Follow-up & Low risk \\
& $\begin{array}{l}\text { Follow-ups conducted for both index and reference groups at } 6, \\
12,18, \text { and } 24 \text { months }\end{array}$
\end{tabular}

18. Statistical tests Unclear risk

Unable to determine appropriateness due to unjustified, complex data analysis and unreported follow-up outcome data

19. Compliance High risk

Compliance not insured. Dose-response analysis conducted but results uninterruptible

\begin{tabular}{|c|c|c|}
\hline 20. Outcome measures & Low risk & All predetermined outcome measures were reported. \\
\hline 21. Selection Bias (population) & Unclear risk & $\begin{array}{l}\text { Participants were recruited from multiple AIDS service organiza- } \\
\text { tions, community mental health centers, HIV medical providers, } \\
\text { and gay and lesbian centers, and may be disproportionate be- } \\
\text { tween index and reference groups, although reported baseline } \\
\text { demographic characteristics were uniform between groups }\end{array}$ \\
\hline 22. Selection bias (time) & Low risk & Recruited at same time. Randomized. \\
\hline 23. Randomization & Low risk & $\begin{array}{l}\text { Stratified randomization procedure on education, CD4 count, } \\
\text { and ethnic minority status }\end{array}$ \\
\hline 24. Allocation concealment & Unclear risk & Not reported. \\
\hline
\end{tabular}

Interventions for improving employment outcomes for workers with HIV (Review) 
Martin 2012 (Continued)

\begin{tabular}{|c|c|c|}
\hline 25. Adjustment for confounding & High risk & Not adjusted for gender; only $9-10 \%$ female in both groups. \\
\hline 26. Incomplete outcome data & High risk & $\begin{array}{l}\text { All follow-up outcome data missing. Only baseline data provided } \\
\text { with generalized summaries in results section }\end{array}$ \\
\hline
\end{tabular}

Nannungi 2013

\begin{tabular}{ll}
\hline Methods & Longitudinal, prospective cohort Study (CBA study) \\
\hline Participants & 482 participants were recruited (July 2008 to August 2009) as consecutive, new clinic \\
& patients recently evaluated for ART from 2 HIV clinics in Kampala, Uganda (Reach Out \\
& Mbuya and Mulago Immune Suppression Syndrome Clinic) \\
& $\begin{array}{l}\text { Index: } 257 \text { HIV+ persons initiating ART with CD4 count }<250 \text { cells } / \mathrm{mm}^{3}(\mathrm{WHO} \\
\text { disease stage III or IV) } \\
\text { Control: } 225 \mathrm{HIV}+\text { persons pre-ART with CD4 count }<400 \mathrm{cells} / \mathrm{mm}^{3}\end{array}$ \\
\hline
\end{tabular}

Interventions

All participants received HIV primary medical care (monitoring and treatment of infections and prescription of prophylactic medications)

Index: ART plus HIV primary medical care

Control: HIV primary medical care

Outcomes

All participants underwent structured interview concerning background characteristics, physical and mental health status, and economic outcomes. Health data abstracted from patient medical records and Medical Outcomes Study HIV Health Survey. Assessments taken at 0,6 , and 12 months

Employment:

1. Work status; having engaged in work activity in previous 7 days (binary yes or no)

2. Weekly income; last payment and number of weeks worked for this payment

Other health-related economic outcomes:

3. Health interefence with ability to work in last month (4-point scale from 'never' to 'most of the time')

Notes

Infectious Diseases Institute Makerere University (Kampala, Uganda)

Uganda National Council of Science and Technology (Uganda)

Rand Corporation (CA, USA)

Participants received 6000 Uganda Shillings ( USD 2.50) for completion of each assessment

Risk of bias

\begin{tabular}{|c|c|c|}
\hline Bias & Authors' judgement & Support for judgement \\
\hline 14. Blinding (Subjects) & Unclear risk & $\begin{array}{l}\text { No blinding, however due to a dichoto- } \\
\text { mous outcome of employed or unem- } \\
\text { ployed in past } 7 \text { days, this should not have } \\
\text { affected the results }\end{array}$ \\
\hline
\end{tabular}

Interventions for improving employment outcomes for workers with HIV (Review) 
Nannungi 2013 (Continued)

\begin{tabular}{|l|l|l|l}
\hline 15. Blinding (outcome assessors) & Low risk & $\begin{array}{l}\text { No blinding, objective outcomes should } \\
\text { have been unaffected by lack of outcome } \\
\text { assessor blinding }\end{array}$ \\
\hline
\end{tabular}

16. Retrospective unplanned subgroup Low risk analysis

No evidence of retrospective unplanned subgroup analysis.

\begin{tabular}{l|l|l}
\hline 17. Follow-up & Unclear risk & $\begin{array}{l}\text { Follow-up conducted at } 0,6, \text { and } 12 \\
\text { months. 36\% attrition. }\end{array}$ \\
\hline $\begin{array}{l}\text { 18. Statistical tests } \\
\text { 19. Compliance }\end{array}$ & Low risk & $\begin{array}{l}\text { Two-tailed t-tests, Chi }{ }^{2} \text { tests, paired t-test, } \\
\text { McNemar's test. }\end{array}$ \\
\hline Unclear risk & Low risk & $\begin{array}{l}\text { As ART adherence is required for survival, } \\
\text { compliance, although not monitored. is } \\
\text { highly likely }\end{array}$ \\
\hline 20. Outcome measures & Lill predetermined outcome measures were \\
\hline
\end{tabular}

\begin{tabular}{|c|c|c|}
\hline 21. Selection Bias (population) & Low risk & $\begin{array}{l}\text { Non-randomized, non-blinded recruit- } \\
\text { ment of consecutive new clinic clients re- } \\
\text { cently evaluated for ART }\end{array}$ \\
\hline
\end{tabular}

\begin{tabular}{l|l|l} 
22. Selection bias (time) & Low risk & All participant recruitment July 2008 to
\end{tabular}
August 2009.

23. Randomization Low risk

Non-randomized, ART group and control group predetermined by health status and WHO stages of disease criteria

24. Allocation concealment High risk

Non-randomization. Did not report the use of adequate sequence generation or allocation concealment techniques

25. Adjustment for confounding Unclear risk

Study adjusted for changes in physical health status, age, gender, education, relationship status, and CD4 count. However, did not account for SES or mental health confounders

26. Incomplete outcome data Unclear risk

$36 \%$ attrition, analysis included attrition weights for dropouts derived from study completion and baseline measures associated with ART

Baseline comparability

High risk

As expected, baseline health differences were present between the index and refer-

Interventions for improving employment outcomes for workers with HIV (Review) 
Nannungi 2013 (Continued)

ence groups due to disease progression and need for treatment. Higher percentage of index group was married or in a committed relationship than control group. Higher percentage of control group working and higher weekly income at baseline than index group. Analysis adjusted for change in physical health status

Thirumurthy 2011

\begin{tabular}{ll}
\hline Methods & CBA study \\
\hline Participants & $\begin{array}{l}1543 \text { adult HIV+ persons, plus } 54 \text { caretakers and } 67 \text { children (Tamil Nadu, India) } \\
\text { Index Group: } 515 \\
\text { Control Group: } 723 \\
\text { A total of } 1238 \text { participants were included in the final analysis }\end{array}$ \\
\hline
\end{tabular}

Interventions

Intervention: Pharmacological, ART and home visits for ART adherence support

- Clinical care: routine medical care, diagnosis, and treatment of opportunistic infections

- Nutritional supplement: nutritional assessment, counseling, macronutrient/ micronutrient supplements

- Home-based care: home visits for encouraging participants to make monthly hospital visits, social service connection for income-generating activities, legal services, and housing

Control: All of the above except for ART and home visits for ART adherence support because CD 4 counts were above 200 and ART was not indicated

Outcomes Employment:

1. Whether participants took part in economic activities during the week prior to interview

2. Number of hours they worked during the week prior to interview

3. Individual income earned in the past 30 days

4. Individual income earned in the past 6 months

Health status:

1. Body mass index

2. CD4 cell count

3. ART initiation date

Notes

*** Participants were not required to be employed at the time of the study, however the study measured economic outcomes related to ART

Risk of bias

Bias

Authors' judgement Support for judgement

Interventions for improving employment outcomes for workers with HIV (Review) 
Thirumurthy 2011 (Continued)

\begin{tabular}{|c|c|c|}
\hline 14. Blinding (Subjects) & Low risk & $\begin{array}{l}\text { No blinding, however due to a dichotomous outcome of em- } \\
\text { ployment or non-employment, this should not have affected the } \\
\text { results }\end{array}$ \\
\hline 15. Blinding (outcome assessors) & Low risk & $\begin{array}{l}\text { No blinding. Objective outcomes that should have been unaf- } \\
\text { fected by blinding }\end{array}$ \\
\hline $\begin{array}{l}\text { 16. Retrospective unplanned subgroup } \\
\text { analysis }\end{array}$ & Low risk & No additional analysis. \\
\hline 17. Follow-up & Low risk & Same time period. $68.66 \%$ present for interviews at 24 months \\
\hline 18. Statistical tests & Unclear risk & $\begin{array}{l}\text { Mean difference and standard error. Contacted authors for fur- } \\
\text { ther interpertation but did not receive response }\end{array}$ \\
\hline 19. Compliance & Unclear risk & $\begin{array}{l}\text { Compliance to ART was not reported. However, ART partic- } \\
\text { ipants did receive home visits to encourage ART adherence. } \\
\text { ART adherence is required for survival, therefore compliance, } \\
\text { although not monitored, is likely }\end{array}$ \\
\hline 20. Outcome measures & Low risk & All previously determined outcomes were reported. \\
\hline 21. Selection Bias (population) & Low risk & $\begin{array}{l}\text { Selected from same population. (Tamil Nadu Family Contin- } \\
\text { uum Care Program) }\end{array}$ \\
\hline 22. Selection bias (time) & Low risk & Recruited at the same time. \\
\hline 23. Randomization & High risk & $\begin{array}{l}\text { Non-randomized study. Participants were predetermined by } \\
\text { health status and CD4 counts }\end{array}$ \\
\hline 24. Allocation concealment & Unclear risk & Non-randomized. \\
\hline 25. Adjustment for confounding & High risk & $\begin{array}{l}\text { Adjusted for gender. No adjustment for differences in disease } \\
\text { severity. No adjustments for differences for SES. No adjustments } \\
\text { for differences in age }\end{array}$ \\
\hline 26. Incomplete outcome data & Unclear risk & $\begin{array}{l}34.34 \% \text { attrition in index group addressed. No attrition data } \\
\text { reported for controls }\end{array}$ \\
\hline Baseline comparability & Unclear risk & $\begin{array}{l}\text { Female percentage was } 42 \% \text { in the index group and } 65 \% \text { in the } \\
\text { reference group. Percentage of those who completed secondary } \\
\text { education was } 28 \% \text { in the index group and } 27 \% \text { in the reference } \\
\text { group. CD } 4 \text { counts at baseline were } 128.2 \text { for the index group } \\
\text { and } 465.6 \text { for the reference group }\end{array}$ \\
\hline
\end{tabular}

ART: antiretroviral therapy

CBA: controlled before-after study

Interventions for improving employment outcomes for workers with HIV (Review) 
HIV+ persons: persons living with HIV

RCT: randomized controlled trial

SES: socioeconomic status

WHO: World Health Organization

Characteristics of excluded studies [ordered by study ID]

\begin{tabular}{|c|c|}
\hline Study & Reason for exclusion \\
\hline Ajithkumar 2007 & No control group. \\
\hline Bernell 2005 & Not a RCT or CBA study. \\
\hline Escovitz 2005 & Kirk Employment Empowerment Project. No control group. \\
\hline Goldman 2004 & No control group. \\
\hline Herdt 1999 & Study about AIDS prevention; not an HIV employment outcome intervention \\
\hline Hergenrather 2013 & No control group. \\
\hline Lee 2005 & $\begin{array}{l}\text { We sought unpublished raw data specific to HIV from the author but received none. The published data } \\
\text { on general chronic diseases was not relevant to the other studies in the review }\end{array}$ \\
\hline Martin 2003 & Not an intervention study. \\
\hline Martin 2005 & Summary of ongoing study later published as Martin 2012. \\
\hline Maticka-Tyndale 2002 & All results were qualitative. \\
\hline Resch 2011 & Non-intervention, modeling study. \\
\hline Rosen 2004 & Not an intervention study. \\
\hline Rosen 2010 & No control group. \\
\hline Rosen 2014 & No control group. \\
\hline Rosolen 2002 & Not an intervention study. \\
\hline Rueda 2012 & Not an intervention study. \\
\hline Thirumurthy 2013 & Not an intervention study. \\
\hline Van der Borght 2006 & Not a RCT or CBA study. \\
\hline
\end{tabular}


(Continued)

Van der Borght $2010 \quad$ Not a RCT or CBA study.

CBA: controlled before-after study

RCT: randomized controlled trial

Characteristics of studies awaiting assessment [ordered by study ID]

Baran 2012

\begin{tabular}{|c|c|}
\hline Methods & Controlled before-after study \\
\hline Participants & 196,350 employees $>18$ years of age (USA) \\
\hline Interventions & Intervention: Pharmacological, ART \\
\hline Outcomes & $\begin{array}{l}\text { Employment: } \\
\text { 1. Sick leave } \\
\text { 2. Short-term disability } \\
\text { 3. Long-term disability } \\
\text { ART cost }\end{array}$ \\
\hline Notes & $\begin{array}{l}\text { Poster presentation only. Contact author for full text and further unpublished outcome data. However, the author } \\
\text { responded that he was unable to provide any unpublished data without the specific permission of AbbVie Pharma- } \\
\text { ceutical Group. AbbVie was contacted for authorization. Richard from AbbVie group is investigating my request. } \\
\text { AbbVie would not release data for external publication or use }\end{array}$ \\
\hline \multicolumn{2}{|l|}{ Borwein 2010} \\
\hline Methods & Not known \\
\hline Participants & Not known \\
\hline Interventions & Not known \\
\hline Outcomes & Not known \\
\hline Notes & $\begin{array}{l}\text { Original search produced only abstracts. Contacted author but received no response. Additionally NM sought hard } \\
\text { copies in Canada, and only poster abstracts were located from the Canadian Journal of Infectious Diseases \& Medical } \\
\text { Microbiology. Study was still in progress in 2010, but no further publication has been made }\end{array}$ \\
\hline
\end{tabular}


Paul-Ward 2005

\begin{tabular}{ll}
\hline Methods & Not known \\
\hline Participants & 48 HIV+ people from supportive living facilities (USA) \\
\hline Interventions & Intervention: ESD program \\
\hline Outcomes & Not known \\
\hline Notes & Study still in progress as of 2005. No later publication found. Contacted author but received no response \\
\hline
\end{tabular}

\section{Popiel 2010}

\begin{tabular}{ll}
\hline Methods & Not known \\
\hline Participants & Not known \\
\hline Interventions & Not known \\
\hline Outcomes & Not known \\
\hline Notes & $\begin{array}{l}\text { Original search produced only abstracts. Contacted author but received no response. Additionally NM sought } \\
\text { hard copies in Canada, and only abstracts were located from the Canadian Journal of Infectious Diseases \& Medical } \\
\text { Microbiology. }\end{array}$ \\
\hline
\end{tabular}


DATA ANDANALYSES

Comparison 1. HIV+ utilizing ART versus healthy (non-HIV+)

\begin{tabular}{|c|c|c|c|c|}
\hline Outcome or subgroup title & $\begin{array}{l}\text { No. of } \\
\text { studies }\end{array}$ & $\begin{array}{c}\text { No. of } \\
\text { participants }\end{array}$ & Statistical method & Effect size \\
\hline 1 Regaining Employment & 1 & & Odds Ratio (Fixed, 95\% CI) & Totals not selected \\
\hline $1.18-5$ years pre-ART & 1 & & Odds Ratio (Fixed, 95\% CI) & $0.0[0.0,0.0]$ \\
\hline $1.22-1.5$ years pre-ART & 1 & & Odds Ratio (Fixed, 95\% CI) & $0.0[0.0,0.0]$ \\
\hline $1.30 .5-0.0$ years pre-ART & 1 & & Odds Ratio (Fixed, 95\% CI) & $0.0[0.0,0.0]$ \\
\hline $1.40 .0-0.5$ years post-ART & 1 & & Odds Ratio (Fixed, 95\% CI) & $0.0[0.0,0.0]$ \\
\hline $1.50 .5-1$ year post-ART & 1 & & Odds Ratio (Fixed, 95\% CI) & $0.0[0.0,0.0]$ \\
\hline $1.61 .5-2$ years post-ART & 1 & & Odds Ratio (Fixed, 95\% CI) & $0.0[0.0,0.0]$ \\
\hline $1.73 .5-4$ years post-ART & 1 & & Odds Ratio (Fixed, 95\% CI) & $0.0[0.0,0.0]$ \\
\hline 2 Days working per month & 1 & & Mean Difference (Fixed, 95\% CI) & Totals not selected \\
\hline $2.124-19$ months pre-ART & 1 & & Mean Difference (Fixed, 95\% CI) & $0.0[0.0,0.0]$ \\
\hline 2.2 6-1 months pre-ART & 1 & & Mean Difference (Fixed, 95\% CI) & $0.0[0.0,0.0]$ \\
\hline 2.30 months & 1 & & Mean Difference (Fixed, 95\% CI) & $0.0[0.0,0.0]$ \\
\hline $2.41-6$ months post-ART & 1 & & Mean Difference (Fixed, 95\% CI) & $0.0[0.0,0.0]$ \\
\hline $2.519-24$ months post-ART & 1 & & Mean Difference (Fixed, 95\% CI) & $0.0[0.0,0.0]$ \\
\hline 3 Resides in Surveillance Area & 1 & & Odds Ratio (Fixed, 95\% CI) & Totals not selected \\
\hline 3.1 5-8 years pre-ART & 1 & & Odds Ratio (Fixed, 95\% CI) & $0.0[0.0,0.0]$ \\
\hline $3.22-1.5$ years pre-ART & 1 & & Odds Ratio (Fixed, 95\% CI) & $0.0[0.0,0.0]$ \\
\hline $3.30 .5-0.0$ years pre-ART & 1 & & Odds Ratio (Fixed, 95\% CI) & $0.0[0.0,0.0]$ \\
\hline $3.40 .0-0.5$ years post-ART & 1 & & Odds Ratio (Fixed, 95\% CI) & $0.0[0.0,0.0]$ \\
\hline $3.50 .5-1$ year post-ART & 1 & & Odds Ratio (Fixed, 95\% CI) & $0.0[0.0,0.0]$ \\
\hline $3.61 .5-2$ years post-ART & 1 & & Odds Ratio (Fixed, 95\% CI) & $0.0[0.0,0.0]$ \\
\hline 3.7 3.5-4 years post-ART & 1 & & Odds Ratio (Fixed, 95\% CI) & $0.0[0.0,0.0]$ \\
\hline 4 Job-loss Spells & 1 & & Hazard Ratio (Fixed, 95\% CI) & Totals not selected \\
\hline
\end{tabular}

Comparison 2. HIV+ utilizing ART versus HIV+ pre-ART

\begin{tabular}{|c|c|c|c|c|}
\hline Outcome or subgroup title & $\begin{array}{l}\text { No. of } \\
\text { studies }\end{array}$ & $\begin{array}{c}\text { No. of } \\
\text { participants }\end{array}$ & Statistical method & Effect size \\
\hline $\begin{array}{l}1 \text { Employment at } 12 \text { months } \\
\text { follow-up }\end{array}$ & 2 & & Odds Ratio (Fixed, 95\% CI) & $1.75[1.44,2.12]$ \\
\hline 2 Hours worked in past week & 1 & & Mean Difference (Fixed, 95\% CI) & Totals not selected \\
\hline 2.16 months follow-up & 1 & & Mean Difference (Fixed, 95\% CI) & $0.0[0.0,0.0]$ \\
\hline 2.212 months follow-up & 1 & & Mean Difference (Fixed, 95\% CI) & $0.0[0.0,0.0]$ \\
\hline 2.318 months follow-up & 1 & & Mean Difference (Fixed, 95\% CI) & $0.0[0.0,0.0]$ \\
\hline 2.424 months follow-up & 1 & & Mean Difference (Fixed, 95\% CI) & $0.0[0.0,0.0]$ \\
\hline
\end{tabular}

Interventions for improving employment outcomes for workers with HIV (Review) 


\section{Analysis I.I. Comparison I HIV+ utilizing ART versus healthy (non-HIV+), Outcome I Regaining Employment.}

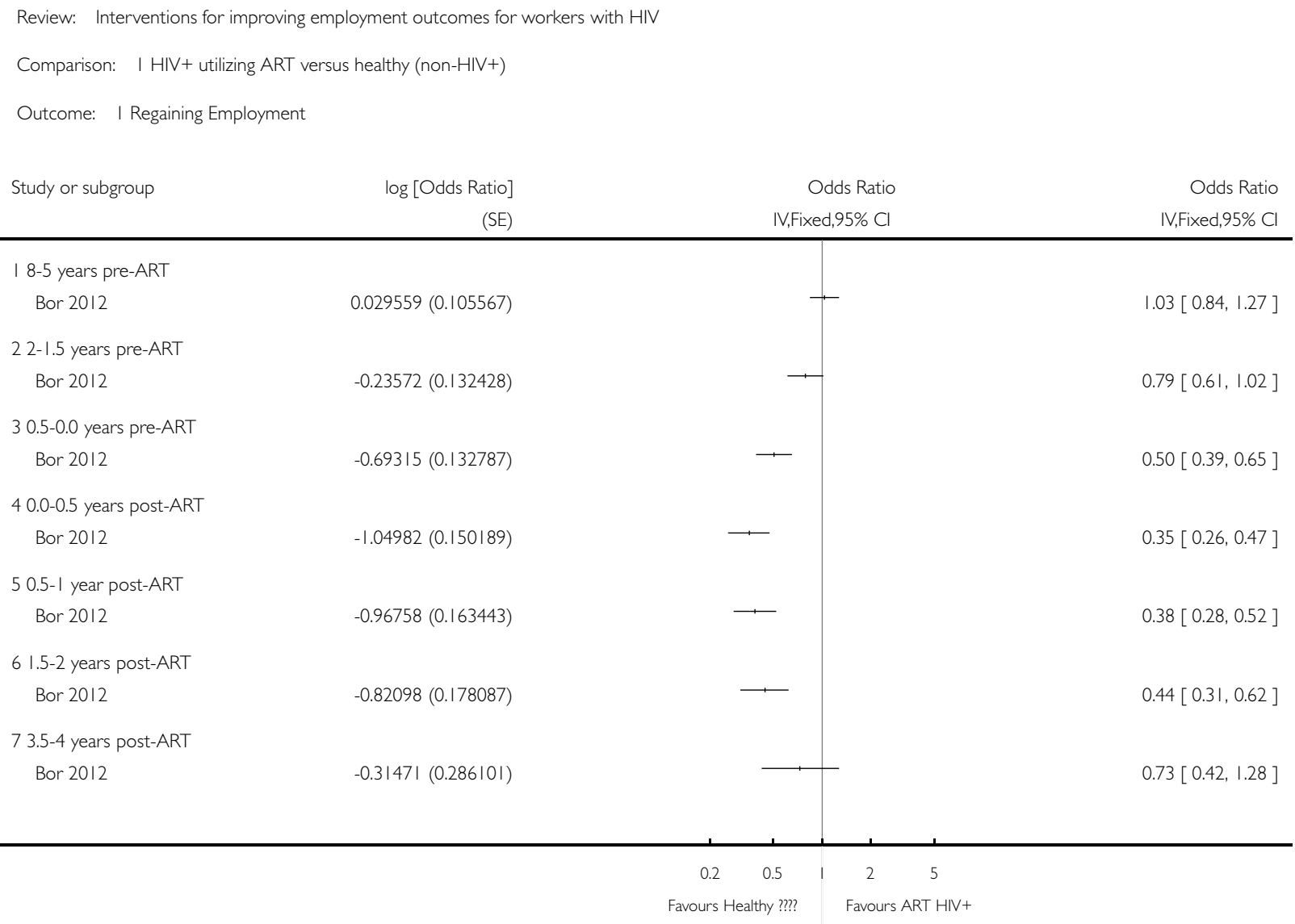


Analysis I.2. Comparison I HIV+ utilizing ART versus healthy (non-HIV+), Outcome 2 Days working per month.

Review: Interventions for improving employment outcomes for workers with HIV

Comparison: I HIV+ utilizing ART versus healthy (non-HIV+)

Outcome: 2 Days working per month

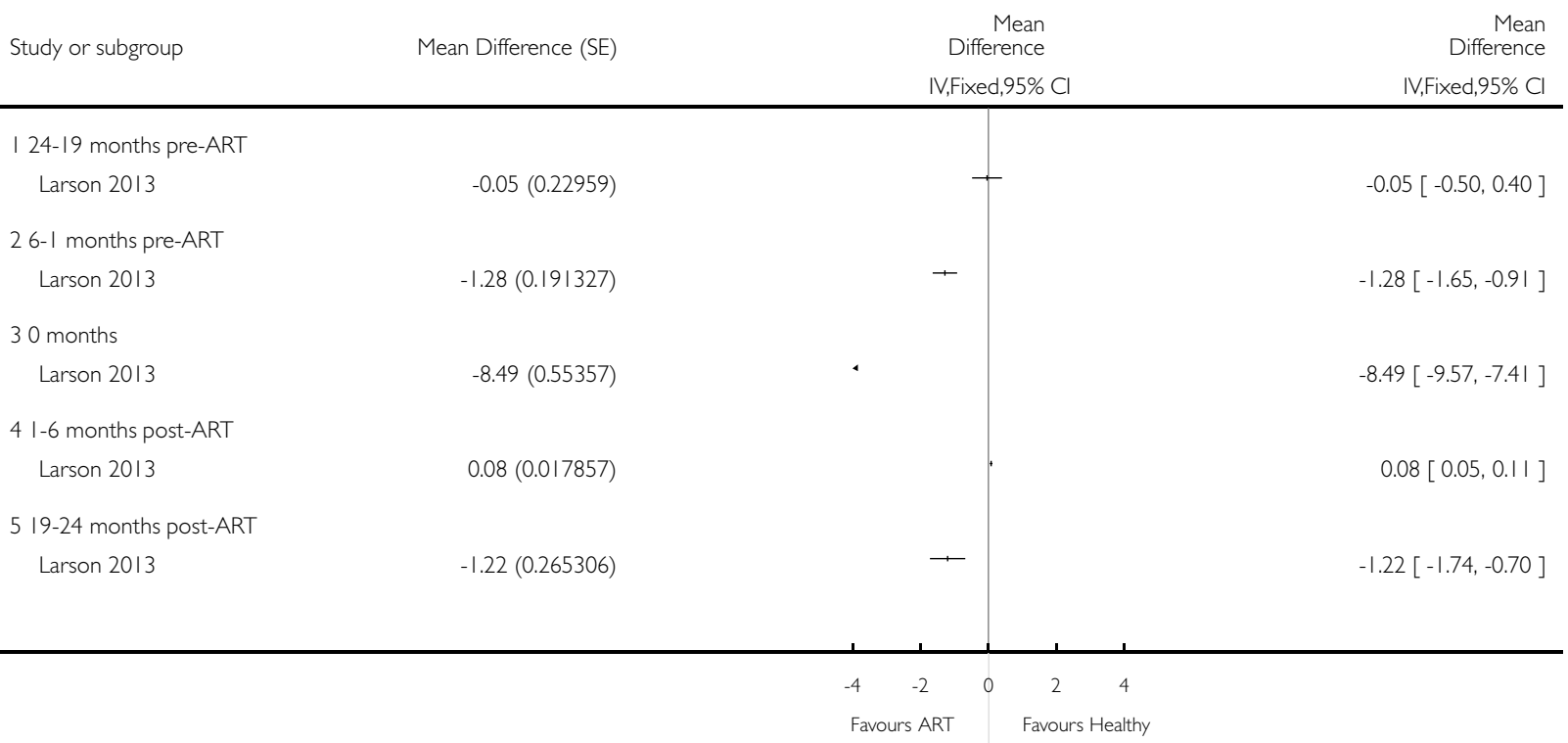


Analysis I.3. Comparison I HIV+ utilizing ART versus healthy (non-HIV+), Outcome 3 Resides in Surveillance Area.

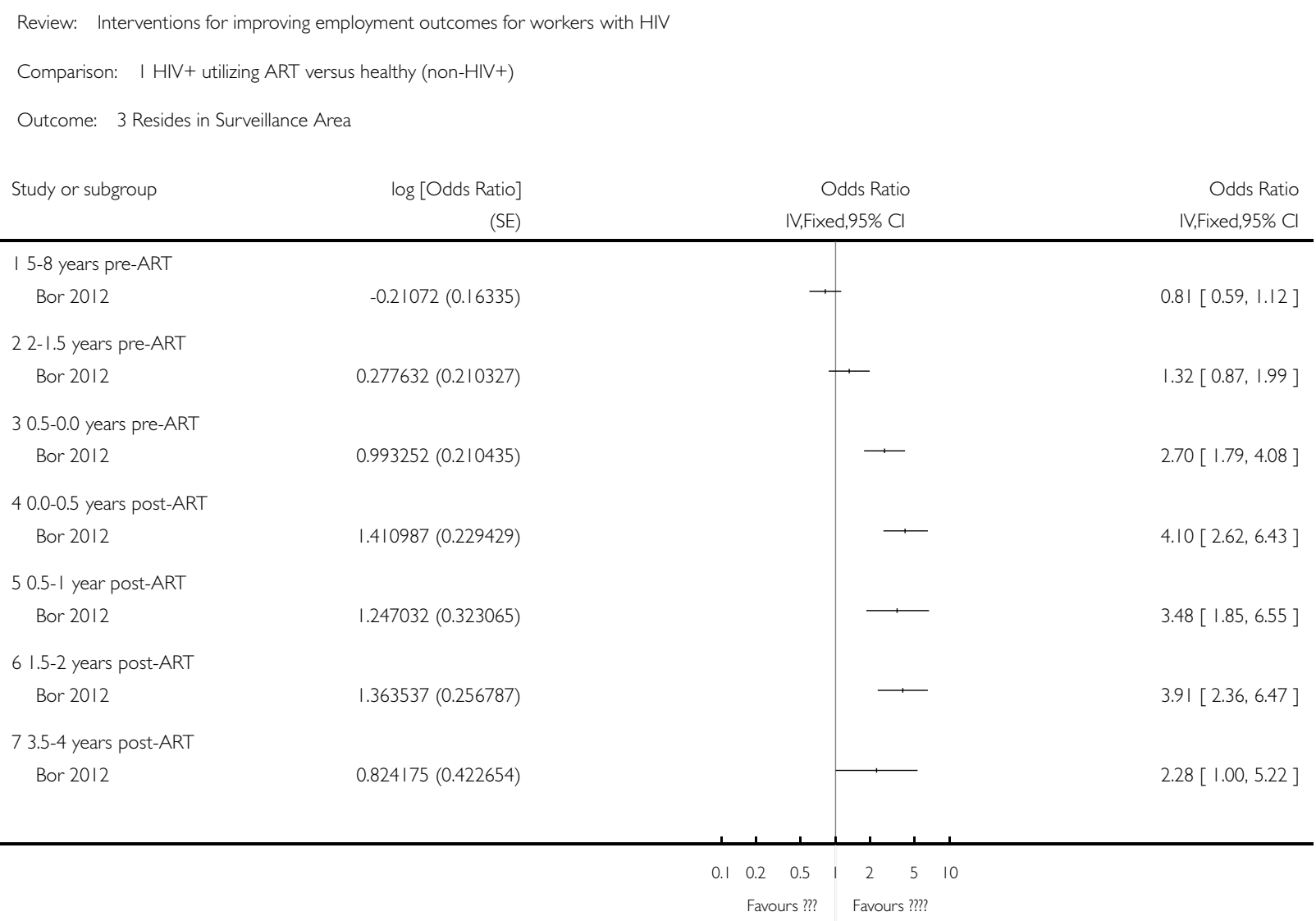


Analysis I.4. Comparison I HIV+ utilizing ART versus healthy (non-HIV+), Outcome 4 Job-loss Spells.

Review: Interventions for improving employment outcomes for workers with HIV

Comparison: I HIV+ utilizing ART versus healthy (non-HIV+)

Outcome: 4 Job-loss Spells

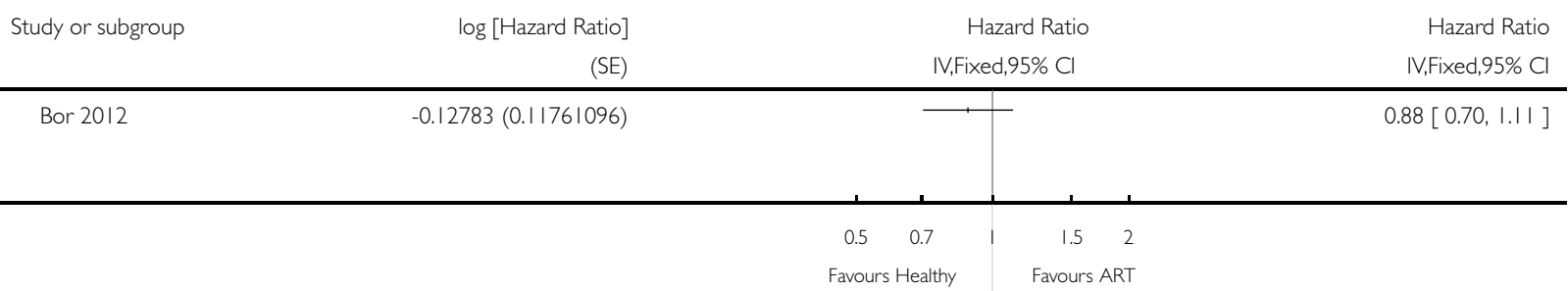

Analysis 2.I. Comparison 2 HIV+ utilizing ART versus HIV+ pre-ART, Outcome I Employment at I2 months follow-up.

Review: Interventions for improving employment outcomes for workers with HIV

Comparison: $2 \mathrm{HIV}+$ utilizing ART versus $\mathrm{HIV}+$ pre-ART

Outcome: | Employment at 12 months follow-up

$\begin{array}{cr}\begin{array}{r}\text { Study or subgroup } \\ \text { Linnemayr 2013 }\end{array} & 0.6313(0.1258) \\ \text { Nannungi 2013 } & 0.4447(0.1556)\end{array}$

Total $(95 \% \mathrm{CI})$

Heterogeneity: $\mathrm{Chi}^{2}=0.87, \mathrm{df}=\mathrm{I}(\mathrm{P}=0.35) ; \mathrm{I}^{2}=0.0 \%$

Test for overall effect: $Z=5.70(P<0.0000 I)$

Test for subgroup differences: Not applicable

IV,Fixed,95\% Cl IV,Fixed,95\% Cl

SE) IV,Fixed,95\% C

$\begin{array}{ll}60.5 \% & 1.88[1.47,2.41] \\ 39.5 \% & 1.56[1.15,2.12]\end{array}$

$100.0 \%$

$1.75[1.44,2.12]$ 


\section{Analysis 2.2. Comparison 2 HIV+ utilizing ART versus HIV+ pre-ART, Outcome 2 Hours worked in past week.}

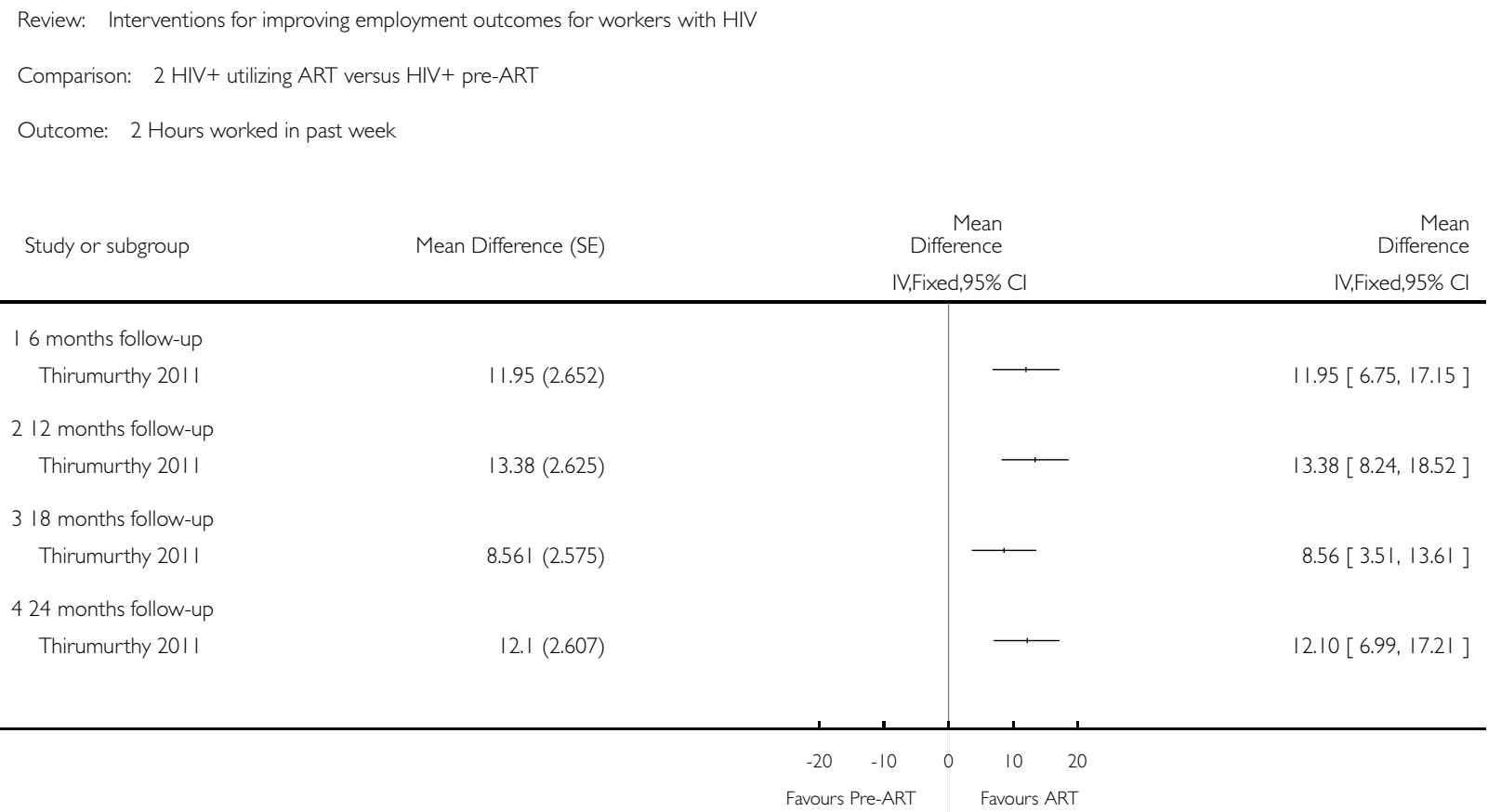

\section{ADDITIONAL TABLES}

Table 1. GRADE ratings for determining the quality of the evidence

\begin{tabular}{|c|c|c|c|c|c|c|c|}
\hline Comparison & $\begin{array}{l}\text { Limitations } \\
\text { (Risk of bias } \\
\text { in studies) }\end{array}$ & $\begin{array}{l}\text { Directness of } \\
\text { evidence }\end{array}$ & $\begin{array}{l}\text { Consistency } \\
\text { between } \\
\text { studies }\end{array}$ & $\begin{array}{l}\text { Precision of } \\
\text { effect size }\end{array}$ & $\begin{array}{l}\text { Publication } \\
\text { bias }\end{array}$ & $\begin{array}{l}\text { Consider- } \\
\text { ations for up- } \\
\text { grading obser- } \\
\text { vational stud- } \\
\text { ies }\end{array}$ & $\begin{array}{l}\text { Level of Evi- } \\
\text { dence }\end{array}$ \\
\hline $\begin{array}{l}\text { HIV+ ART } \\
\text { vs. Healthy ( } 2 \\
\text { Studies) }\end{array}$ & $\begin{array}{l}\text { HIGH risk of } \\
\text { bias. Non- } \\
\text { random- } \\
\text { ized retrospec- } \\
\text { tive studies } \\
\text { of cohort data. } \\
\text { Non-blinded } \\
\text { but } \\
\text { should not af- } \\
\text { fect the results } \\
\text { of the study as }\end{array}$ & $\begin{array}{l}\text { No limita- } \\
\text { tions. Popula- } \\
\text { tions in com- } \\
\text { par- } \\
\text { ison: Kenyan } \\
\text { tea work- } \\
\text { ers (predomi- } \\
\text { nate employer } \\
\text { in district) \& } \\
\text { South African } \\
\text { general popu- }\end{array}$ & $\begin{array}{l}\text { Results consis- } \\
\text { tent in both } \\
\text { studies. Sub- } \\
\text { group analysis } \\
\text { was not appli- } \\
\text { cable } \\
\text { NO DOWN- } \\
\text { GRADE }\end{array}$ & $\begin{array}{l}\text { Wide con- } \\
\text { fidence inter- } \\
\text { vals. } \\
\text { DOWN- } \\
\text { GRADE }\end{array}$ & $\begin{array}{l}\text { Not applica- } \\
\text { ble; only two } \\
\text { studies. } \\
\text { NO DOWN- } \\
\text { GRADE }\end{array}$ & $\begin{array}{l}\text { Small } \\
\text { intervention } \\
\text { partic- } \\
\text { ipant numbers } \\
\text { potentially in- } \\
\text { flate the mag- } \\
\text { nitude of the } \\
\text { effect } \\
\text { Dose-effect re- } \\
\text { lation was not }\end{array}$ & VERY LOW \\
\hline
\end{tabular}

Interventions for improving employment outcomes for workers with HIV (Review) 
Table 1. GRADE ratings for determining the quality of the evidence (Continued)

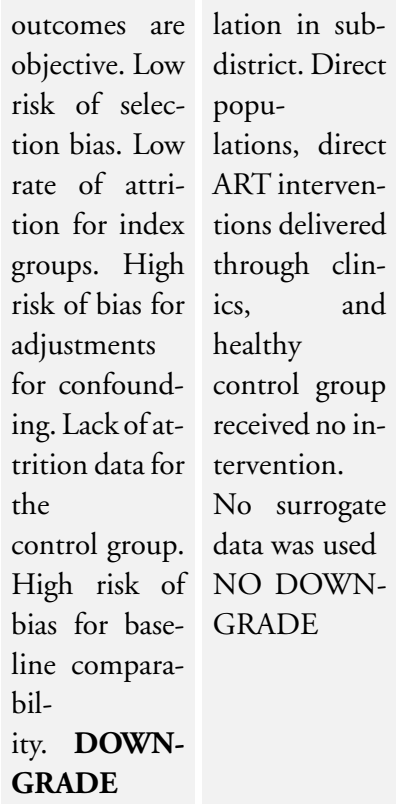

\begin{tabular}{|c|c|c|c|c|c|c|}
\hline $\begin{array}{l}\text { HIV+ } \\
\text { ART vs. Pre- } \\
\text { ART (3 Stud- } \\
\text { ies) }\end{array}$ & $\begin{array}{l}\text { HIGH risk of } \\
\text { bias. Non- } \\
\text { randomized } \\
\text { prospective } \\
\text { cohort studies. } \\
\text { No blinding, } \\
\text { however } \\
\text { results should } \\
\text { be unaffected } \\
\text { due to objec- } \\
\text { tive, dichoto- } \\
\text { mous out- } \\
\text { comes. Low } \\
\text { risk of selec- } \\
\text { tion bias. Low } \\
\text { rate of attri- } \\
\text { tion for index. } \\
\text { Unclear risk } \\
\text { for a lack of } \\
\text { attrition data } \\
\text { for the control } \\
\text { groups. High } \\
\text { risk of bias for } \\
\text { baseline com- } \\
\text { parabil- } \\
\text { ity. DOWN- } \\
\text { GRADE }\end{array}$ & $\begin{array}{l}\text { No outlying, } \\
\text { indirect ev- } \\
\text { idence. Con- } \\
\text { trol groups re- } \\
\text { ceived } \\
\text { standard care. } \\
\text { No surrogate } \\
\text { data used in } \\
\text { any study } \\
\text { NO DOWN- } \\
\text { GRADE }\end{array}$ & $\begin{array}{l}\text { Results consis- } \\
\text { tent in all } 3 \\
\text { studies. } \\
\text { NO DOWN- } \\
\text { GRADE }\end{array}$ & $\begin{array}{l}\text { NO DOWN- } \\
\text { GRADE }\end{array}$ & $\begin{array}{l}\text { All } 3 \text { studies } \\
\text { produced evi- } \\
\text { dence of the } \\
\text { positive effect } \\
\text { of ART on } \\
\text { employment, } \\
\text { how- } \\
\text { ever we did } \\
\text { not judge this } \\
\text { to be biased } \\
\text { to file drawer } \\
\text { phenomenon. } \\
\text { None } \\
\text { of the studies } \\
\text { had pharma- } \\
\text { ceutical fund- } \\
\text { ing } \\
\text { or any known } \\
\text { conflicts of in- } \\
\text { terest } \\
\text { NO DOWN- } \\
\text { GRADE }\end{array}$ & $\begin{array}{l}\text { Small } \\
\text { intervention } \\
\text { partic- } \\
\text { ipant numbers } \\
\text { potentially in- } \\
\text { flate the mag- } \\
\text { nitude of the } \\
\text { effect } \\
\text { Dose-effect re- } \\
\text { lation was not } \\
\text { explored as no } \\
\text { data on dosage } \\
\text { was provided } \\
\text { Incomplete } \\
\text { analysis for } \\
\text { confounders. } \\
\text { Studies in- } \\
\text { dividually ad- } \\
\text { justed for dif- } \\
\text { ferent and } \\
\text { limited } \\
\text { confounders } \\
\text { NO UPGRADE }\end{array}$ \\
\hline
\end{tabular}

explored as no data on dosage was provided No analysis for confounders.

NO

UPGRADE
VERY LOW produced evi- intervention positive effect ipant numbers ever we did effect not judge this Dose-effect reto be biased lation was not of the studies Incomplete had pharma- analysis for ceutical fund- confounders. ng Studies inor any known dividually adconflicts of in- justed for difterest ferent and NO DOWN- limited $\mathrm{NO}$ GRADE 
Table 1. GRADE ratings for determining the quality of the evidence (Continued)

\begin{tabular}{|c|c|c|c|c|c|c|c|}
\hline $\begin{array}{l}\text { Vocational } \\
\text { Interven- } \\
\text { tion vs. None } \\
\text { (1 study) }\end{array}$ & $\begin{array}{l}\text { High risk of } \\
\text { bias. Al- } \\
\text { location con- } \\
\text { cealment and } \\
\text { loss to follow- } \\
\text { up not } \\
\text { reported. No } \\
\text { blinding and } \\
\text { evidence of se- } \\
\text { lective report- } \\
\text { ing } \\
\text { DOWN- } \\
\text { GRADE }\end{array}$ & $\begin{array}{l}\text { No } \\
\text { outlying, indi- } \\
\text { rect evidence } \\
\text { due to single- } \\
\text { study compar- } \\
\text { ison. Control } \\
\text { group received } \\
\text { standard care. } \\
\text { Outcome } \\
\text { data limi- } \\
\text { tations due to } \\
\text { missing fol- } \\
\text { low-up data } \\
\text { and complex, } \\
\text { confusing re- } \\
\text { porting. } \\
\text { DOWN- } \\
\text { GRADE }\end{array}$ & $\begin{array}{l}\text { Only one } \\
\text { study; } \\
\text { complete ho- } \\
\text { mogeneity } \\
\text { NO DOWN- } \\
\text { GRADE }\end{array}$ & $\begin{array}{l}\text { Poorly re- } \\
\text { ported, mini- } \\
\text { mal outcome } \\
\text { data. } \\
\text { DOWN- } \\
\text { GRADE }\end{array}$ & $\begin{array}{l}\text { No evidence } \\
\text { of publication } \\
\text { bias. } \\
\text { NO DOWN- } \\
\text { GRADE }\end{array}$ & $\begin{array}{l}\text { Randomized } \\
\text { study. } \\
\text { NOT APPLI- } \\
\text { CABLE }\end{array}$ & VERY LOW \\
\hline
\end{tabular}

\section{A P P E N D I CES}

\section{Appendix I. MEDLINE (PubMed) search strategy}

14 March 2012 (by Leena Isotalo)

\#1 HIV Infections[MeSH] OR HIV[MeSH] OR hiv[tw] OR hiv-1*[tw] OR hiv-2*[tw] OR hiv1[tw] OR hiv2[tw] OR hiv infect*[tw] OR human immunodeficiency virus[tw] OR human immunedeficiency virus[tw] OR human immuno-deficiency virus[tw] OR human immune-deficiency virus[tw] OR ((human immun*[tw]) AND (deficiency virus[tw])) OR acquired immunodeficiency syndrome[tw] OR acquired immunedeficiency syndrome[tw] OR acquired immuno-deficiency syndrome[tw] OR acquired immune-deficiency syndrome[tw] OR ((acquired immun*[tw]) AND (deficiency syndrome[tw])) OR HIV/AIDS[tw]

\#2 absenteeism[tw] OR absenteeism [MeSH] OR “work disability”[tw] OR "sick leave"[tw] OR "sick leave"[MeSH] OR "sickness absence" [tw] OR employment [MeSH] OR employment [tw] OR “re-employment” [tw] OR unemployment [MeSH] OR unemployment [tw] OR unemployed[tw] OR employability[tw] OR employable[tw] OR employee* [tw] OR “work capacity”[tw] OR "occupational health" [MesH] OR "occupational health services" [MeSH] OR "return to work" [tw] OR "retirement" [tw] OR "work status" [tw] OR “occupational medicine”[MeSH] OR “job satisfaction” [tw] OR “work ability”[tw] OR workability[tw] OR "work activity”[tw] OR “work retention” [tw] OR “job retention”[tw] OR “job loss”[tw] OR “job performance”[tw] OR “rehabilitation, vocational” $[\mathrm{MeSH}]$ OR "work rehabilitation" $[\mathrm{tw}]$

\#3 (work[ti] OR worker*[tw] OR worki*[tw] OR workplace*[tw] OR worksite*[tw] OR occupation*[tw] OR "Occupational Groups"[Mesh]) AND (“disability management"[tw] OR "Rehabilitation”[Mesh:NoExp] OR "rehabilitation” [Subheading] OR "psychological intervention" $[\mathrm{tw}]$ OR "psychological interventions" $[\mathrm{tw}] \mathrm{OR}$ "motivational interviewing” [tw] OR "self management” $\mathrm{tw}$ ] OR “behaviour change" [tw] OR “Occupational Therapy”[Mesh]) OR “work accommodation” [tw] OR “work modification” [tw] \#4 \#1 AND (\#2 OR \#3)

\#5 randomized controlled trial[pt] OR controlled clinical trial[pt] OR randomized[tiab] OR placebo[tiab] OR drug therapy[sh] OR randomly[tiab] OR trial[tiab] OR groups[tiab] NOT (animals [mh] NOT humans [mh])

Interventions for improving employment outcomes for workers with HIV (Review)

Copyright @ 2015 The Cochrane Collaboration. Published by John Wiley \& Sons, Ltd. 
\#6 (effect* ${ }^{*}$ tw] OR control[tw] OR controls*[tw] OR controla*[tw] OR controle*[tw] OR controli*[tw] OR controll*[tw] OR evaluation*[tw] OR program*[tw]) OR “Cohort Studies"[Mesh] OR "Intervention Studies”[Mesh] OR “Comparative Study" [Publication Type] OR "Evaluation Studies as Topic”[Mesh:NoExp] OR “Evaluation Studies” [Publication Type] OR "follow up” [tw]

\#7 \#4 AND \#5

\#8 \#4 AND \#6

\#9 \#7 OR \#8

Updated Search 9 December 2014 (by Kaisa Neuvonen)

\begin{tabular}{|c|c|c|}
\hline Search & Query & Items found \\
\hline$\# 10$ & $\begin{array}{l}\text { \#9 AND (“2013/11/06”[Date - Entrez] : “3000”[Date - En- } \\
\text { trez]) }\end{array}$ & 154 \\
\hline \#9 & \#7 OR \#8 & 3249 \\
\hline$\# 8$ & \#4 AND \#6 & 3018 \\
\hline$\# 7$ & \#4 AND \#5 & 1033 \\
\hline \#6 & $\begin{array}{l}\text { (effect*[tw] OR control[tw] OR controls*[tw] OR con- } \\
\text { trola*[tw] OR controle*[tw] OR controli*[tw] OR con- } \\
\text { troll*[tw] OR evaluation*[tw] OR program*[tw]) OR “Co- }^{*} \text { hort Studies"[Mesh] OR "Intervention Studies"[Mesh] OR } \\
\text { "Comparative Study" [Publication Type] OR "Evaluation } \\
\text { Studies as Topic"[Mesh:NoExp] OR "Evaluation Studies" } \\
\text { [Publication Type] OR "follow up" [tw] }\end{array}$ & 11397938 \\
\hline \#5 & $\begin{array}{l}\text { randomized controlled trial[pt] } \text { OR controlled clinical } \\
\text { trial[pt] OR randomized[tiab] OR placebo[tiab] OR } \\
\text { drug therapy[sh] OR randomly[tiab] OR trial[tiab] OR } \\
\text { groups[tiab] NOT (animals [mh] NOT humans [mh]) }\end{array}$ & 2993018 \\
\hline \#4 & \#1 AND (\#2 OR \#3) & 4626 \\
\hline
\end{tabular}

\#3 (work[ti] OR worker*[tw] OR worki*[tw] OR work- 30610

place* $^{*}[\mathrm{tw}]$ OR worksite*[tw] OR occupation*[tw] OR

"Occupational Groups"[Mesh]) AND (“disability management”[tw] OR “Rehabilitation”[Mesh:NoExp] OR "rehabilitation" [Subheading] OR "psychological intervention" [tw] OR "psychological interventions" [tw] OR "motivational interviewing" [tw] OR "self management" [tw] OR "behaviour change" [tw] OR "Occupational Therapy”[Mesh]) OR “work accommodation" [tw] OR "work modification” [tw]

\#2 absenteeism[tw] OR absenteeism [MeSH] OR "work dis- 226105 ability" [tw] OR "sick leave"[tw] OR “sick leave”[MeSH] OR "sickness absence" [tw] OR employment [MeSH] OR employment [tw] OR "re-employment"[tw] OR unemployment [MeSH] OR unemployment [tw] OR unemployed[tw] OR employability[tw] OR employable[tw] OR 
employee*[tw] OR "work capacity" [tw] OR "occupational health" $[\mathrm{MesH}] \mathrm{OR}$ "occupational health services” $[\mathrm{MeSH}]$ OR "Return to work" [MeSH] OR "return to work" [tw] OR "retirement" $[\mathrm{tw}]$ OR "work status" $[\mathrm{tw}]$ OR "occupational medicine" [MeSH] OR "job satisfaction" [tw] OR "work ability" [tw] OR workability[tw] OR "work activity" [tw] OR “work retention” [tw] OR “job retention”[tw] OR "job loss”[tw] OR “job performance”[tw] OR "rehabilitation, vocational” $[\mathrm{MeSH}] \mathrm{OR}$ "work rehabilitation” [tw] hiv-1*[tw] OR hiv-2*[tw] OR hiv1[tw] OR hiv2[tw] OR hiv infect* $[\mathrm{tw}]$ OR human immunodeficiency virus[tw] OR human immunedeficiency virus[tw] OR human immuno-deficiency virus[tw] OR human immune-deficiency virus[tw] OR ((human immun*[tw]) AND (deficiency virus[tw])) OR acquired immunodeficiency syndrome[tw] OR acquired immunedeficiency syndrome[tw] OR acquired immuno-deficiency syndrome[tw] OR acquired immune-deficiency syndrome $[\mathrm{tw}]$ OR ((acquired immun*[tw]) AND (deficiency syndrome[tw])) OR HIV/AIDS[tw]

\section{Appendix 2. Cochrane Central Register of Controlled Trials (CENTRAL) search strategy}

9 October 2012 (by Leena Isotalo)

\#1 hiv or "hiv-1*" or "hiv-2*" or hiv1 or hiv2 or "hiv infect*" or "human immunodeficiency virus" or "human immunedeficiency virus" or "human immuno-deficiency virus" or "human immune-deficiency virus":ti,ab,kw (Word variations have been searched)

9102

\#2 MeSH descriptor: [HIV] explode all trees

2250

\#3 MeSH descriptor: [HIV Infections] explode all trees

6728

\#4 ("human immun*" and "deficiency virus") or "acquired immunodeficiency syndrome" or "acquired immunedeficiency syndrome" or "acquired immuno-deficiency syndrome" or "acquired immune-deficiency syndrome" or ("acquired immun*" and "deficiency syndrome") or "HIV/AIDS"

2340

\#5 \#1 or \#2 or \#3 or \#4

9863

\#6 MeSH descriptor: [Absenteeism] explode all trees

370

\#7 MeSH descriptor: [Sick Leave] explode all trees

334

\#8 MeSH descriptor: [Employment] explode all trees

958

\#9 MeSH descriptor: [Unemployment] explode all trees

54

\#10 MeSH descriptor: [Occupational Health] explode all trees

318

\#11 MeSH descriptor: [Occupational Health Services] explode all trees

Interventions for improving employment outcomes for workers with HIV (Review)

Copyright @ 2015 The Cochrane Collaboration. Published by John Wiley \& Sons, Ltd. 
\#12 MeSH descriptor: [Occupational Medicine] explode all trees

57

\#13 MeSH descriptor: [Rehabilitation, Vocational] explode all trees

305

\#14 absenteeism or "work disability" or "sick leave" or "sickness absence" or employment or "re-employment" or unemployment or unemployed or employability or employable or employee* or "work capacity" or "return to work" or "retirement" or "work status" or "job satisfaction" or "work ability" or workability or "work activity" or "work retention" or "job retention" or "job loss" or "job performance" or "work rehabilitation"

6822

$\# 15 \# 6$ or $\# 7$ or \#8 or \#9 or \#10 or \#11 or \#12 or \#13 or \#14

7297

\#16 MeSH descriptor: [Occupational Groups] explode all trees

5326

\#17 MeSH descriptor: [Rehabilitation] this term only

270

\#18 Any MeSH descriptor with qualifier(s): [Rehabilitation - RH] in all MeSH products

11494

\#19 MeSH descriptor: [Occupational Therapy] explode all trees

452

\#20 work*:ti (Word variations have been searched)

4338

\#21 worker* or worki* or workplace* or worksite* or occupation*

16400

\#22 "psychological intervention" or "psychological interventions" or "motivational interviewing" or "self management" or "behaviour change" or accommodation or modification

12075

\#23 \#16 or \#20 or \#21

22100

\#24 "disability management"

18

\#25 \#17 or \#18 or \#19 or \#22 or \#24

23331

\#26 \#23 and \#25

3171

\#27 \#15 or \#26

9556

\#28 \#5 and \#27

245

limited to:

Cochrane Central Register of Controlled Trials (Central)

80

Interventions for improving employment outcomes for workers with HIV (Review) 


\section{Appendix 3. EMBASE search strategy}

20 September 2012 (by Leena Isotalo)

(\#1) 'human immunodeficiency virus infection'/exp OR 'human immunodeficiency virus'/exp OR hiv:ab,ti OR 'hiv-1':ab,ti OR 'hiv2':ab,ti OR 'human immunodeficiency virus':ab,ti OR 'human immuno-deficiency virus':ab,ti OR 'human immunedeficiency virus': ab,ti OR 'human immune-deficiency virus':ab,ti OR 'acquired immune-deficiency syndrome':ab,ti OR 'acquired immunedeficiency syndrome':ab,ti OR 'acquired immunodeficiency syndrome' $a b, t i$ OR 'acquired immuno-deficiency syndrome' $: a b, t i$ OR 'hiv/aids' $a b, t i$ 364,281

(\#2) 'absenteeism'/de OR 'medical leave'/de OR 'work disability'/de OR 'employment'/exp OR 'unemployment'/de OR 'work capacity'/ de OR 'occupational health'/de OR 'employability'/de OR 'job accommodation'/de OR 'vocational rehabilitation'/de OR 'occupational health service'/de OR 'occupational health nursing'/de OR 'occupational medicine'/de OR 'industrial medicine'/de OR 'job adaptation'/ de OR 'retirement'/de OR 'job satisfaction'/de OR 'job performance'/de OR absenteeism:ab,ti OR 'work disability':ab,ti OR 'sick leave':ab,ti OR 'sickness absence':ab,ti OR employment:ab,ti OR 're-employment':ab,ti OR unemployment:ab,ti OR unemployed:ab,ti OR employability:ab,ti OR employable:ab,ti OR employee*:ab,ti OR 'work capacity':ab,ti OR 'occupational health services':ab,ti OR 'return to work':ab,ti OR retirement:ab,ti OR 'work status':ab,ti OR 'job satisfaction':ab,ti OR 'work ability':ab,ti OR workability:ab,ti OR 'work activity':ab,ti OR 'work retention':ab,ti OR 'job retention':ab,ti OR 'job loss':ab,ti OR 'job performance':ab,ti OR 'vocational rehabilitation':ab,ti OR 'work rehabilitation':ab,ti OR 'work accommodation':ab,ti OR 'work modification':ab,ti 238,611

(\#3) work*:ab,ti OR occupation*:ab,ti OR 'work environment'/de OR 'work'/de OR 'workplace'/exp OR 'occupation and occupation related phenomena'/de OR 'occupation'/exp OR 'occupational health'/exp AND ('disability management':ab,ti OR rehabilitation: de,ab,ti OR 'psychological intervention':ab,ti OR 'psychological interventions':ab,ti OR 'motivational interviewing':ab,ti OR 'self management':ab,ti OR behavio* NEAR/3 chang* OR 'occupational therapy')

52,567

(\#4) \#1 AND (\#2 OR\#3)

5,044

(\#5) random* OR factorial* OR crossover* OR cross NEXT/1 over* OR placebo* OR doubl* NEAR/1 blind* OR singl* NEAR/1 blind OR assign* OR allocat* OR volunteer* OR 'crossover procedure'/de OR 'double-blind procedure'/de OR 'single-blind procedure'/de OR 'randomized controlled trial'/de

$1,405,159$

(\#6) effect* OR control* OR evaluation* OR program* OR 'cohort analysis'/de OR 'intervention study'/de OR 'comparative study'/ de OR 'comparative effectiveness'/de OR 'intermethod comparison'/de OR 'follow up'

$12,732,170$

(\#7) \#4 AND \#5

456

(\#8) \#4 AND \#6

3,435

(\#9) \#7 OR \#8

3,497

(\#10) 'editorial'/it OR 'letter'/it OR 'note'/it OR 'short survey'/it OR 'nonhuman'/de

$5,767,119$

(\#11) \#9 NOT \#10

3,228

(\#12) \#11 AND [embase]/lim

2,110

Updated Search 9 December 2014 (by Kaisa Neuvonen)

(\#1) 'human immunodeficiency virus infection'/exp OR 'human immunodeficiency virus'/exp OR hiv:ab,ti OR 'hiv-1':ab,ti OR 'hiv2':ab,ti OR 'human immunodeficiency virus':ab,ti OR 'human immuno-deficiency virus' :ab,ti OR 'human immunedeficiency virus': ab,ti OR 'human immune-deficiency virus':ab,ti OR 'acquired immune-deficiency syndrome':ab,ti OR 'acquired immunedeficiency syndrome':ab,ti OR 'acquired immunodeficiency syndrome':ab,ti OR 'acquired immuno-deficiency syndrome':ab,ti OR 'hiv/aids' :ab,ti

404,528

Interventions for improving employment outcomes for workers with HIV (Review) 
(\#2) 'absenteeism'/de OR 'medical leave'/de OR 'work disability'/de OR 'employment'/exp OR 'unemployment'/de OR 'work capacity'/ de OR 'occupational health'/de OR 'employability'/de OR 'job accommodation'/de OR 'vocational rehabilitation'/de OR 'occupational health service'/de OR 'occupational health nursing'/de OR 'occupational medicine'/de OR 'industrial medicine'/de OR 'job adaptation'/ de OR 'retirement'/de OR 'job satisfaction'/de OR 'job performance'/de OR absenteeism:ab,ti OR 'work disability'ab,ti OR 'sick leave':ab,ti OR 'sickness absence':ab,ti OR employment:ab,ti OR 're-employment':ab,ti OR unemployment:ab,ti OR unemployed:ab,ti OR employability:ab,ti OR employable:ab,ti OR employee*:ab,ti OR 'work capacity':ab,ti OR 'occupational health services':ab,ti OR 'return to work':ab,ti OR retirement:ab,ti OR 'work status':ab,ti OR 'job satisfaction':ab,ti OR 'work ability':ab,ti OR workability:ab,ti OR 'work activity':ab,ti OR 'work retention':ab,ti OR 'job retention':ab,ti OR 'job loss':ab,ti OR 'job performance':ab,ti OR 'vocational rehabilitation':ab,ti OR 'work rehabilitation':ab,ti OR 'work accommodation':ab,ti OR 'work modification':ab,ti

262,028

(\#3) work*:ab,ti OR occupation*:ab,ti OR 'work environment'/de OR 'work'/de OR 'workplace'/exp OR 'occupation and occupation related phenomena'/de OR 'occupation'/exp OR 'occupational health'/exp AND ('disability management':ab,ti OR rehabilitation: de,ab,ti OR 'psychological intervention':ab,ti OR 'psychological interventions':ab,ti OR 'motivational interviewing':ab,ti OR 'self management':ab,ti OR behavio* NEAR/3 chang* OR 'occupational therapy')

61,328

(\#4) \#1 AND (\#2 OR \#3)

5,936

(\#5) random* OR factorial* OR crossover* OR cross NEXT/1 over* OR placebo* OR doubl* NEAR/1 blind* OR singl* NEAR/1 blind OR assign* OR allocat* OR volunteer* OR 'crossover procedure'/de OR 'double-blind procedure'/de OR 'single-blind procedure'/de OR 'randomized controlled trial'/de

$1,674,549$

(\#6) effect* OR control* OR evaluation* OR program* OR 'cohort analysis'/de OR 'intervention study'/de OR 'comparative study'/ de OR 'comparative effectiveness'/de OR 'intermethod comparison'/de OR 'follow up'

$12,986,661$

(\#7) \#4 AND \#5

575

(\#8) \#4 AND \#6

3,588

(\#9) \#7 OR \#8

3,686

(\#10) 'editorial'/it OR 'letter'/it OR 'note'/it OR 'short survey'/it OR 'nonhuman'/de

$6,412,344$

(\#11) \#9 NOT \#10

3,434

Interventions for improving employment outcomes for workers with HIV (Review)

Copyright @ 2015 The Cochrane Collaboration. Published by John Wiley \& Sons, Ltd. 
(\#12) \#11 AND [embase]/lim

2,519

(\#13) \#11 AND [embase]/lim AND [6-11-2013]/sd NOT [9-12-2014]/sd

354

\section{Appendix 4. OSH UPDATE search strategy}

25 September 2012 (by Leena Isotalo)

\begin{tabular}{|c|c|c|}
\hline$\# 1$ & 3152 & $\begin{array}{l}\text { GW\{hiv OR “hiv-1*” OR "hiv-2*” OR hiv1 OR hiv2 OR "HIV/AIDS” OR HUMAN IMMUNODEFICIENCY } \\
\text { VIRUS OR HUMAN IMMUNEDEFICIENCY VIRUS OR HUMAN IMMUNE-DEFICIENCY VIRUS OR } \\
\text { HUMAN IMMUNO-DEFICIENCY VIRUS OR HUMAN IMMUN* DEFICIENCY VIRUS OR ACQUIRED } \\
\text { IMMUNODEFICIENCY SYNDROME OR ACQUIRED IMMUNEDEFICIENCY SYNDROME OR AC- } \\
\text { QUIRED IMMUNO-DEFICIENCY SYNDROME OR ACQUIRED IMMUNE-DEFICIENCY SYNDROME } \\
\text { OR ACQUIRED IMMUN* DEFICIENCY SYNDROME\} }\end{array}$ \\
\hline$\# 2$ & 89805 & $\begin{array}{l}\text { GW absenteeism OR work disability OR sick leave OR sickness absence OR employment OR re-employment } \\
\text { OR unemployment OR unemployed OR employability OR employable OR employee* OR work capacity OR } \\
\text { occupational health service* OR return-to-work OR retirement OR work status OR job satisfaction OR work } \\
\text { ability OR workability OR work activity OR work retention OR job retention OR job loss OR job performance } \\
\text { OR vocational rehabilitation OR work rehabilitation\} }\end{array}$ \\
\hline$\# 3$ & 47230 & $\begin{array}{l}\text { GW\{disability OR rehabilitation OR psycholog* OR motivational OR self management OR behaviour OR behavior } \\
\text { OR therapy OR work accommodation OR work modification\} }\end{array}$ \\
\hline \#4 & 87611 & GW\{workplace* OR worksite* OR work place* OR work site* OR organisation* OR organization*\} \\
\hline$\# 5$ & 19111 & GW\{occupation OR occupations\} \\
\hline \#6 & 392334 & $\begin{array}{l}\text { GW }\{\text { random* OR trial* OR groups OR effect* OR effici* OR control* OR evaluat* OR program* OR cohort* } \\
\text { OR intervention* OR compar* OR follow-up\} }\end{array}$ \\
\hline \#7 & 732455 & DC $\{$ OUCISD OR OUHSEL OR OUNIOC OR OUNIOS OR OURILO $\}$ \\
\hline$\# 8$ & 193459 & \#2 OR \#3 OR \#4 OR \#5 \\
\hline$\# 9$ & 1355 & \#1 AND \#8 \\
\hline$\# 10$ & 970 & \#9 AND \#6 \\
\hline \#11 & 764 & \#10 AND \#7 \\
\hline
\end{tabular}

Interventions for improving employment outcomes for workers with HIV (Review)

Copyright $\odot 2015$ The Cochrane Collaboration. Published by John Wiley \& Sons, Ltd. 


\section{CONTRIBUTIONSOFAUTHORS}

RR conducted the abstract appraisal, full-text review, data extraction, data analysis, and article write-up. We divided duplicate investigation of abstracts, full text, data, and article commentary evenly between EO and NM. RR is the guarantor of this review.

\section{DECLARATIONSOF INTEREST}

Rachel Robinson: None known.

Emmanuel Okpo: None known.

Nomusa Mngoma: None known.

\section{DIFFERENCES BETWEEN PROTOCOLANDREVIEW}

The protocol for this review was published under the title, "Work arrangements for sustaining employment in workers with HIV", however, we changed the title to "Interventions for improving employment outcomes for workers with HIV" as we considered this title to more accurately describe the review.

We also included studies that allowed for participants to be unemployed at the time of diagnosis, in order to provide the most comprehensive picture of employment outcomes by accounting for job loss trends prior to diagnosis. This alteration accounts for the effects of HIV on employment being prior to diagnosis. 